\title{
Las diversas lecturas del concepto de violencia política en razón de género en México (2010-2020)
}

\author{
The various readings of the concept of \\ gender-based political violence \\ in Mexico (2010-2020)
}

\author{
Gloria Jovita Guadarrama Sánchez \\ (D) http://orcid.org/0000-0003-3726-5646 \\ El Colegio Mexiquense, A. C., México,gguadarr@cmq.edu.mx \\ Emma del Carmen Aguilar Pinto \\ http://orcid.org/0000-0001-9339-6849 \\ El Colegio Mexiquense, A. C., México, eaguilar@cmq.edu.mx
}

*Autor para

correspondencia :

Gloria Jovita Guadarrama

Sánchez

Recepción: 27/05/20

Aprobación: 26/01/20

Publicación: 26/04/21

$\circledast \oplus \Theta \Theta$
Abstract: Political violence by gender reasons constitutes a menace for the rights of women acting in the political sphere and has harmful effects in society. However, it is difficult to understand what should be considered political violence. The aim of this text is to examine different perspectives about the meaning of gender-based political violence. The discussion is supported on reviews of scholarly research, books and articles published in Mexico between 2010 and 2020 , driven by an analysis of the central points of the concept. The core issues of this discussion contribute to understand the social construction and institutionalization of gender-based political violence, particularly in the Mexican academic and political spheres, and to highlight its relevance for democratic procedures.

Key words: gender-based political violence, gender, political culture, women rights, political participation.

Resumen: La violencia política en razón de género constituye una amenaza para los derechos de las mujeres que participan en la esfera política y tiene efectos nocivos en la sociedad. No obstante, resulta difícil aproximarse a lo que debe ser considerado como violencia política. El objetivo de este texto es examinar distintas perspectivas sobre los significados del concepto; su discusión se sustenta en la revisión de estudios académicos, libros y artículos publicados en México entre 2010 y 2020, mediante un análisis que marca puntos nodales en el concepto. Los ejes centrales de la discusión contribuyen al entendimiento de su construcción social e institucionalización, particularmente en los ámbitos académico y político, y destacan su relevancia para los procedimientos democráticos.

Palabras clave: violencia política, género, cultura política, derechos de las mujeres, participación política. 


\section{Introducción}

En las últimas décadas en México se ha incrementado el uso del concepto violencia política en razón de género para adscribirlo a los casos en los que las mujeres encuentran obstáculos para ejercer sus derechos políticos. Un problema central en la discusión es la imprecisión y ambigüedad en su uso, lo cual deja ver una falta de consenso sobre las cuestiones básicas que lo definen; este texto intenta hacer una aproximación a cómo se ha comenzado a leer el concepto en la academia y en la sociedad mexicanas. Para explicar su construcción social, se identifican las perspectivas teóricas y las vías frecuentes de aproximación a su estudio. Una de ellas está relacionada con el aumento de la participación de las mujeres en política, espacio que a lo largo de la historia había sido masculinamente generizado, pero que alimentado por tendencias internacionales y movimientos feministas ha permitido la presencia cada vez mayor de mujeres. Otra vía guarda relación con la noción de empoderamiento de las mujeres (Fernández, 2017; Novo, 2010); en ella se advierte la capacidad de agencia de las mujeres y sus posibilidades de incursionar en espacios masculinos por habilidades personales y rasgos de liderazgo que les permiten destacar en la política. La tercera vía encuentra explicación en la desmedida violencia que sacude al territorio nacional y se reproduce en la violencia de género, como expresión de la cultura. En todas ellas, se halla implícita la noción de derechos humanos con especial atención en los derechos políticos, marcando la posibilidad que debieran tener todas las personas, independientemente de su género, de disfrutar los derechos en igualdad de condiciones (Fernández, 2015).

La primera vía considera que la mayor presencia de mujeres en la política ha visibilizado el fenómeno de violencia política y, paradójicamente, ha provocado la resistencia en los actores e instituciones políticas en una lucha por los espacios de poder, las posiciones y las jerarquías, lo cual se traduce en discriminación, agresión, vulnerabilidad y desventajas, como manifestaciones de lo que se denomina "violencia política en razón de género".

Desde la vía del empoderamiento, el reconocimiento de la desigualdad y discriminación contra las mujeres como construcción social y cultural incentiva las acciones encaminadas a la transformación de relaciones desiguales entre mujeres y hombres. Se mira al empoderamiento como un proceso que busca cambiar la distribución del poder en la esfera pública y terminar con las barreras que dificultan su participación política. Asimismo, se entiende como una estrategia de política pública que configura mecanismos contra la desigualdad desde un nivel personal, colectivo y comunitario 
(Rowlands, 1997). Así, su empoderamiento resulta un factor importante para el desarrollo equitativo, democrático y sostenible de las sociedades. En la tercera vía, la violencia política es percibida como una derivación de la violencia general que campea en el país y es vista como una transferencia de patrones culturales a los espacios de la política.

Con esos elementos, a partir de la idea de su construcción social y de la perspectiva de género como marcos teórico-metodológicos aplicados a la violencia política, se revisan aquí las perspectivas conceptuales que forman parte de la percepción general sobre su significado, las cuales surgen de los usos frecuentes en el discurso académico y en la sociedad. En el marco de la construcción social se reconoce que la forma en la cual se comprende el mundo en que vivimos es resultado del conjunto de ideas, significados, valores y prácticas que han sido establecidas en las sociedades como parte de la actividad humana, las cuales se comparten, son internalizadas y apropiadas, individual y colectivamente (Berger y Luckmann, 1967; 1997; Yáñez, 2010).

El orden donde se inserta y desarrolla la vida cotidiana integra y dota de sentido a las acciones, y es socializado a través de diversos mecanismos; ${ }^{1}$ las representaciones sociales sobre el rol de las mujeres en la vida social forman parte de los sistemas de valores que dan sentido a las acciones; las relaciones son construidas dentro del contexto cultural y pueden ser vistas como prácticas sociales (Vázquez y Díaz, 2012). Desde esa mirada, el concepto violencia politica en razón de género se ha ido conformando de manera inductiva con las experiencias de participación en la acción política (Krook y Restrepo, 2016a), y su significado está vinculado a la forma en la cual se construye el papel del género en la vida pública.

La violencia ejercida contra las mujeres que se incorporan a la política ha estado presente a lo largo de la historia, su libre participación ha sido un proceso prolongado en el cual han enfrentado severas y, en ocasiones, violentas restricciones. Su estudio ha sido abordado desde distintas perspectivas, entre las que destacan los enfoques políticos (Millet, 1971), estructurales

1 La posición sigue las tesis clásicas de Berger y Luckmann (1967 y 1997) de que las vivencias y el conocimiento que se tiene de la realidad son consecuencia de procesos socializados, institucionalizados e internalizados por los sujetos y construidos desde el punto de vista social a partir de la interacción entre las relaciones, los hábitos y las estructuras sociales (Yáñez, 2010). El sentido es modelado por la acción social; las instituciones políticas y económicas confieren, transmiten y hacen obligatorios ciertos sentidos asociados a los fines que están en sus áreas de responsabilidad, los cuales son internalizados como valores comunes e interpretaciones compartidas de la realidad (Berger y Luckmann, 1997). 
(Galtung, 1969; Bourdieu y Wacquant, 2008)² y relacionales; la mayoría de las aproximaciones la asocian a las ideas de poder, dominación o fuerza, ubicándola en el terreno de las relaciones políticas. Desde esos ángulos, la violencia contra las mujeres opera como un mecanismo de poder que mantiene la dominación y sumisión (Scott, 1996). ${ }^{3}$ Otras interpretaciones (Butler, 2004; Conway et al., 1996) ${ }^{4}$ la explican como resultado de la cultura política; Pateman, (1995) y Lagarde (1996) perciben a la democracia como contrato sexual-social coercitivo, visibilizan sistemas democráticos que confinan a las mujeres y toleran, no formalmente, pero sí de facto, la desigualdad de género. En México, los estudios sobre los obstáculos que enfrentan las mujeres para acceder a un encargo son los de Sam (2003 y 2002); Barrera (2011, 2008 y 2003) aborda la exclusión y el control social. En tanto, Massolo (2007) examina los factores que obstaculizan la participación política en el espacio local. A diferencia del uso actual del concepto que involucra varias dimensiones de la violencia en distintos niveles y espacios, los estudios mencionados señalan aspectos y contextos particulares de la violencia.

La que enfrentan las mujeres en política no es algo nuevo; hasta 1890 no había un sólo país en el mundo donde las mujeres pudieran votar. Las movilizaciones para conseguir ese derecho se registran a finales del siglo XIX y en los comienzos del XX, enmarcadas en episodios de lucha y violencia, como es el caso de las sufragistas en Gran Bretaña, quienes enfrentaron insultos, multas, amonestaciones, arrestos, prisión, agresiones y golpes (González, 2009). Hubo que cambiar reglas y conquistar libertades; de manera paralela, el proceso generó planteamientos teóricos sobre sus causas y manifestaciones. Actualmente, los conceptos se reconstruyen en el marco del creciente número de mujeres que acceden y compiten por espacios y poder en las esferas de la política. La afirmación sobre la construcción teórica del

2 Galtung (1969) conceptualizó la violencia como el conjunto de estructuras, a través de las cuales las sociedades institucionalizan el daño, ubicando en este ámbito la subordinación y discriminación de las mujeres. Bourdieu y Wacquant (2008) señalan que las estructuras sociales naturalizan la dominación mediante la violencia simbólica.

3 Scott (1996: 292) explica que el género, como elemento constitutivo de las relaciones sociales, articula las relaciones de poder. El género es un factor de dominación y establece la distribución de poder sobre los recursos materiales y simbólicos.

4 Butler (2004) considera las configuraciones sociales del género como prácticas constantemente reproducidas más o menos negociadas en cada cultura; así los sujetos en las estructuras de la política se construyen mediante prácticas excluyentes. Para Conway et al. (1996), las prácticas han cumplido funciones de exclusión en la vida política. 
concepto considera una distinción entre la noción vivencial de la violencia presente a lo largo de la historia y el "concepto" científico construido como ejercicio teórico dentro de un campo especializado.

Las interpretaciones del concepto están permeadas por la visión de género, la cual destaca la violencia que en diversas esferas de la vida pública y privada sufren las mujeres; en particular la que enfrentan quienes participan en política. Cabe subrayar que el concepto es el resultado de procesos de construcción en cada ámbito político y social, a modo de arreglos institucionales entre los actores y su entorno. El presente artículo se sustenta en la revisión de textos de corte académico publicados recientemente en México, cuyo contenido principal es la violencia política. ${ }^{5}$ Obviamente, existen numerosas publicaciones en medios no académicos, cuya revisión excede los alcances de este análisis.

De manera sustantiva, se trata de un estudio exploratorio que analiza las miradas académicas sobre la violencia política contra las mujeres por razones de género. Del conjunto de textos, 46 incluyen en el título los términos: violencia política, violencia política en razón de género, y violencia política contra las mujeres. Las palabras clave utilizadas con mayor frecuencia son: violencia política contra las mujeres o violencia política de género, mujeres, alcaldesas, cuotas de género. ${ }^{6}$ Las publicaciones corresponden al periodo 2010-2020 cuando se detecta el incremento en los estudios que emplean este concepto.

Se seleccionaron textos publicados en revistas científicas registrados en las bases de datos de Scielo y Redalyc que recuperan la producción en América Latina, así como Scopus; se incluyeron manuales, guías y protocolos publicados por la Cámara de Diputados, el INE y algunos institutos electorales estatales; se consideró que este tipo de publicaciones muestran la perspectiva legal en torno a la violencia política. Se identificaron libros especializados sobre el tema que también se incluyeron en el análisis. ${ }^{7}$ Los

5 Véase Anexo 1. Cuadro Resumen. Estudios sobre violencia política en México (20102020). Todos los anexos y las gráficas se encuentran al final del presente artículo (Nota del editor).

6 Véase Anexo 2. Enfoques teóricos y metodológicos.

7 Las bases de datos revisadas son las que registran la producción científica en ciencias sociales y políticas en Latinoamérica, por ello se considera una muestra confiable de la forma como se ha asumido el concepto de violencia política en la academia en México; no obstante, la selección deja fuera numerosos artículos de revistas de difusión cultural y científica, así como capítulos y libros publicados en otros medios de difusión institucional; obviamente eso limita la propuesta y la interpretación del sector analizado. 
criterios de búsqueda fueron: 1) estudios sobre violencia política por razones de género en México, 2) publicados en el periodo 2010-2020,3) escritos en idioma español. Los descriptores empleados para la búsqueda reproducen las miradas que desde la academia han surgido en torno al concepto de violencia política por razones de género: violencia, violencia política, género, participación política, violencia de género, violencia contra las mujeres, participación política, mujeres (véase Anexo 3). La muestra se integra por 64 estudios, 27 de ellos son artículos, 21 capítulos de libros, 6 libros, un cuaderno de trabajo, una evaluación sobre el proceso electoral a nivel subnacional y ocho documentos entre protocolos y manuales para la atención de la violencia política (véase Gráfica 1 ). Se advierte que los marcos generales y las líneas que estructuran el texto fueron derivados como abstracciones que permiten pasar del ámbito de la expresión discursiva diversa, a una discusión articulada sobre principios comunes.

En la exposición, primero se presentan los conceptos generales de violencia y violencia de género, para luego profundizar en las perspectivas que condensan las ideas centrales del concepto violencia politica en razón de género. ${ }^{8}$ En seguida se exploran los estudios de violencia política en México, se identifican sus marcos conceptuales y los componentes que impregnan el debate actual. La incursión en la discusión de la violencia política no debe ser vista como un mero ejercicio reflexivo, ya que sin avances en la precisión conceptual, el estudio de sus componentes es una tarea imposible; además, al lado de su interés académico, existe un interés sustantivo en los propósitos de justicia social y democracia que forman parte de las aspiraciones nacionales.

8 Al margen de que diversos estudios en Latinoamérica abordan el concepto como violencia contra las mujeres, para México se consideró adecuado emplear el término violencia política por razones de género, que es una categoría más amplia e incluyente (Adrián, 2015). La adopción del concepto en la academia apunta en el mismo sentido que las instancias normativas del país, que procuran el reconocimiento de los derechos político-electorales de toda la ciudadanía, sin distinción o prácticas discriminatorias por cuestiones de identidad o expresiones de género, en condiciones de igualdad y promoviendo la participación en la vida pública nacional (INE, 2018). 


\section{Violencia de género}

En un sentido amplio, violencia es un concepto no fácil de capturar, ya que es polisémico y se caracteriza por su ambigüedad. En términos llanos, alude al uso de la fuerza sobre alguien o sobre algo con un fin particular, e implica un comportamiento que puede dañar a otros. Su origen etimológico proviene del latín violentia que se traduciría como "el uso continuado de la fuerza". La Organización Mundial de la Salud (OMS) establece que "la violencia es el uso intencional de la fuerza física, amenazas contra uno mismo, otra persona, un grupo o una comunidad que tiene como consecuencia o es muy probable que tenga como consecuencia un traumatismo, daños psicológicos, problemas de desarrollo o la muerte" (OMS, 2019: 1).

En una aproximación hacia la violencia contra las mujeres, en México hay un número significativo de encuestas que buscan medirla en diferentes dimensiones del entramado de las interacciones sociales (Castro, 2012; Castro y Casique, 2009). Su aporte radica en hacer visible que no es un asunto individual; generalmente están orientadas hacia el campo de la salud pública; por lo tanto, su objetivo no es explicarla, sino establecer medidas para prevenirla. De hecho, desde 1996, la Asamblea Mundial de Salud la consideró un problema de salud pública, estableciendo metas concretas y medidas de prevención (OPS, 2003).

Las Naciones Unidas definen la violencia contra la mujer como "todo acto de violencia de género que resulte, o pueda tener como resultado un daño físico, sexual o psicológico para la mujer, inclusive las amenazas de tales actos, la coacción o la privación arbitraria de libertad, tanto si se producen en la vida pública como en la privada" (OMS, 2019: 1).

Algunos estudios la ubican en el plano simbólico o cultural; desde la antropología feminista, Segato (2003) apunta hacia una violencia invisible y a la serie de estructuras que la producen y multiplican; la violencia hacia las mujeres reside en una cultura patriarcal, la cual establece marcos que permiten legitimarla y naturalizarla. Así, la violencia es situada en el plano de las relaciones sociales y en el plano de la cultura.

Otros advierten que los estudios en torno a la violencia enfrentan como desafíos la incapacidad en la formulación de políticas públicas para su prevención y las limitaciones de la investigación que se realiza desde la academia (Bermúdez y Evangelista, 2018); y que es necesario conceptualizar "los tipos de violencia en general, y la violencia hacia las mujeres en particular" (Castro, 2012: 21). Con esa intención diferencian entre formas de dominación u opresión y expresiones de violencia, y distinguen la violencia de género 
de otras formas de violencia hacia las mujeres (Castro y Riquer, 2003; Castro, 2012). ${ }^{9}$ Tales retos muestran la necesidad de avanzar en su definición conceptual y de identificar las formas en las que se expresa.

\section{La noción de violencia politica en razón de género, la evolución del concepto}

Diversos análisis consideran que la política es un espacio tenso caracterizado por la violencia en distintas dimensiones y niveles (Pereira, 1974; Talancón, 2009), especialmente cuando se trata de violencia política y procesos electorales (Massolo, 2007; Calderón; 1994). Sobre la violencia contra las mujeres en politica, Krook (2017: 50) y Brockmann (2017: 266) coinciden en señalar que el concepto surge en Bolivia en la década de 2000, y está relacionado con la denuncia que realizó un grupo de concejalas bolivianas, al dar a conocer "el acoso y la violencia que sufrían las mujeres en municipalidades rurales". ${ }^{10}$

Krook y Restrepo (2016b) advierten que se trata de un fenómeno reciente, pero que está ganando terreno en el plano internacional. La definen como "cualquier tipo de agresión física o psicológica que ejercen los responsables de partidos y otros actores políticos en contra de las mujeres, con el fin de obstaculizar su presencia en la vida pública” (Krook y Restrepo, 2016a: 130-131). Los autores apuntan que se busca claramente impedir su participación, y distinguen entre violencia contra las mujeres en política por el hecho de ser mujeres (sean candidatas, activistas, militantes o votantes) y violencia contra las mujeres en elecciones (en campaña o cuando asumen posiciones políticas). Proponen que su análisis debe considerar cuatro dimensiones: violencia física, psicológica, económica y simbólica.

9 La distinción entre violencia hacia las mujeres y violencia de género es importante, ya que son nociones diferentes. En el primer caso, se produce contra la mujer por el sólo hecho de ser mujer y se reproduce en ámbitos como la familia, la sociedad o el Estado. El segundo refiere a una construcción social basada en estereotipos que se asocian a un sexo determinado; Adrián (2015) señala que permite la inclusión de otras categorías sociales como raza, origen étnico, clase, condición social, religión, así como tejer otras interseccionalidades como las minorías, las identidades y las orientaciones sexuales e incluso involucrar la violencia contra los hombres, niñas y niños por lo que resulta un término más amplio e incluyente.

10 El caso de Bolivia resulta paradigmático por varias razones, como la constitución de la Asociación de Concejalas Bolivianas (Acobol) en 1999, que permitió el intercambio de experiencias sobre violencia política en razón de género; así como por el fuerte activismo que impulsó entre sus participantes y por que fue el primer país en aprobar una legislación en 2012 que prohíbe el acoso y la violencia politica en contra de las mujeres. 
Para Cerva (2014: 6), la violencia política en razón de género se constituye por "todas aquellas acciones y/o conductas agresivas cometidas por una persona, o por terceros, que causen daño físico, psicológico o sexual en contra de una mujer o su familia por el simple hecho de participar en la esfera política”.

En las formas enunciadas de concebir la violencia política se nota que aún no hay consenso sobre su significado; en lo que sí existe acuerdo es que no debe ser el costo que tengan que pagar las mujeres por participar en política, y en que abordar este fenómeno permitirá el desarrollo de una cultura, prácticas e instituciones democráticas (Krook y Restrepo, 2016b). Otros estudios sobre la violencia política en América Latina son los de Tello (2019), Quiñones (2018), Albaine (2017), Brockmann (2017), Cueva et al. (2017), Del Valle (2017), Freidenberg y Del Valle (2017), Freidenberg (2017a), Piscopo (2017), Otálora (2017) y García (2014). En ellos se advierte que su significado se concentraba inicialmente en el daño infligido a las mujeres y que en la actualidad es percibido como el conjunto de obstáculos al ejercicio de sus derechos. Interesa también destacar que la discusión del concepto ha ido teniendo mayor arraigo en los países latinoamericanos, mientras que en los países europeos y asiáticos, así como en Estados Unidos y Canadá, ha sido mínima.

Se observa que la noción de violencia política alude a un tipo de violencia que resulta en ocasiones inasible y tiene como fin desalentar a las mujeres de ser o estar políticamente activas; se trata de una violencia poco sancionable, caracterizada por la existencia de mucha tensión, porque la esfera política es un ambiente masculino (Astelarra, 1990; Tarrés, 1998; De Barbieri, 2003; Fernández, 2014); y porque las instituciones no son neutras al género y hay resistencia a abandonar patrones culturales (García, 2017; Tagle, 2017; Fernández, 2014; De Barbieri, 2003). Al final, puede leerse que tanto los estereotipos como los roles de género culturalmente arraigados constituyen obstáculos para las mujeres que acceden a la esfera política y se desempeñan en puestos de poder (García, 2017; Narcía, 2017; López, 2017; Fernández, 2014; Lagunes, 2014; Massolo, 2007). En estos estudios hay coincidencia en destacar la línea sustantiva que representa la cultura como componente del concepto.

Para García (2014), la violencia de género contra las mujeres en los espacios de la política institucional es un fenómeno que se ha visibilizado, debido a las denuncias de mujeres que la han experimentado. García (2014) distingue distintas expresiones en la esfera pública: una es directa (visible) y se manifiesta en formas de acoso para evitar que ejerzan su función, 
así como intimidación, amenazas, violencia física contra ellas o familiares, destrucción de sus bienes, menosprecio de sus opiniones y trato discriminatorio por parte de los medios de comunicación. Otra es indirecta, cuando a las mujeres políticas se les exige más que a los hombres, se les oculta información, se retienen sus pagos o se les limita el presupuesto, se juzga su vida personal o su aspecto físico. Alanís (2017: 233) menciona que el concepto de violencia politica contra las mujeres:

comprende todas aquellas acciones y omisiones (incluida la tolerancia) que, basadas en elementos de género, y dadas en el marco del ejercicio de los derechos políticoelectorales tengan por objeto o resultado menoscabar o anular el reconocimiento, goce o ejercicio de los derechos políticos y de las prerrogativas inherentes a un cargo público.

En el mismo sentido, la Comisión Nacional de los Derechos Humanos de México (CNDH, 2018: 2) estableció que:

la violencia política contra las mujeres comprende todas aquellas acciones u omisiones de personas, servidoras o servidores públicos que se dirigen a una mujer por ser mujer (en razón de género), tienen un impacto diferenciado en ellas o les afectan desproporcionadamente, con el objeto o resultado de menoscabar o anular sus derechos político-electorales, incluyendo el ejercicio del cargo. La violencia política contra las mujeres puede incluir, entre otras, violencia física, psicológica, simbólica, sexual, patrimonial, económica o feminicida.

El tema ocupó también un lugar en la mesa de debates de la Décima Conferencia Regional sobre la Mujer de América Latina y el Caribe (2008) y se consideró que era una limitante para la paridad y la democracia. En esa ocasión, y por primera vez, mujeres políticas de América Latina presentaron sus testimonios para analizar el impacto en sus carreras políticas (Lagunes, 2014).

En la visión actual, un acto de violencia politica se basa en el género cuando se dirige a una mujer, tomando como referencia estereotipos o roles de género; cuando tiene un impacto diferenciado en las mujeres; cuando afecta de manera distinta a las mujeres y a los hombres; y cuando les afecta en forma desproporcionada. Dicha violencia puede tener lugar en cualquier esfera: política, económica, social, cultural o civil. Incluye el ámbito público y el privado, y puede darse en: la familia, unidad doméstica, relación interpersonal, en la comunidad, en un partido o institución política. Puede ser simbólica, verbal, patrimonial, económica, física, sexual, psicológica, y también llevarse a cabo por medio de las tecnologías de la información o en el ciberespacio (Mena et al., 2017; Narcía, 2017). Puede ser perpetrada:

por cualquier tipo de persona o personas, por el Estado o sus agentes, superiores jerárquicos, colegas de trabajo, partidos políticos, medios de comunicación y sus integrantes. La acción violenta puede estar dirigida a una persona o grupo de personas, a su familia o su comunidad (Freidenberg, 2017a: 20). 
Incluso, algunas formas de violencia ocurren cuando existen, registros fraudulentos de candidatas que renuncian a sus cargos para cederlos a suplentes varones; por exigencias de los partidos para que las mujeres firmen renuncias en blanco antes de registrarlas como candidatas; en el registro de mujeres como candidatas en distritos tradicionalmente perdedores, a pesar de que las leyes electorales lo prohíben; por falta de acceso a recursos para financiar las campañas, se oculta información, se desestiman y descalifican las propuestas presentadas por mujeres; existen agresiones verbales discriminatorias, acoso, ataques físicos, violencia sexual e incluso asesinatos, y dimisión o renuncia obligada o amenazada por otras autoridades (Freidenberg, 2018: 59).

En esa visión se aprecia la transición del concepto como agresión y uso de la fuerza física o simbólica contra las mujeres, hacia su significación como actos que vulneran la igualdad de oportunidades. También resulta visible el vínculo del concepto de violencia política en razón de género con los principios sobre los derechos humanos, en particular con el ejercicio de los derechos políticos como metas de la justicia y la democracia.

\section{La perspectiva de los derechos humanos}

La relevancia que tienen los derechos humanos para las sociedades actuales es resultado de distintas trayectorias que comienzan con la adopción de la Declaración Universal de los Derechos Humanos en 1948, como el marco normativo universal para la igualdad y las libertades fundamentales, que fue paulatinamente extendiéndose -mediante acuerdos internacionalesdesde los derechos individuales hasta los derechos cívicos, políticos y sociales (ACNUDH, 2006). ${ }^{11}$ Con ese movimiento, los principios y las demandas sociales por la equidad y la justicia para las mujeres permearon los marcos normativos de los Estados nacionales, resaltando intencionalidades para asegurar sus derechos.

11 La Declaración Universal de Derechos Humanos, instituida en el marco de las Naciones Unidas en 1948, se constituyó gradualmente en una valiosa herramienta para orientar la búsqueda del desarrollo humano, el bienestar y la igualdad de oportunidades. Los cambios en la concepción de los derechos humanos y su ampliación fueron plasmados en el Pacto Internacional de las Naciones Unidas sobre Derechos Civiles y Políticos, y en el Pacto Internacional de las Naciones Unidas sobre Derechos Económicos, Sociales y Culturales, de 1966; así como en acuerdos y convenciones especiales, la Convención sobre los Derechos Políticos de la Mujer, 1953; la Convención sobre la Eliminación de todas las Formas de Discriminación Contra la Mujer, 1981; la Convención Americana sobre Derechos Humanos, 1969; la Convención Interamericana para Prevenir, Sancionar y Erradicar la Violencia contra la Mujer. 
Aunado a estos procesos, en la evolución del concepto de violencia política se ha ido marcando un giro a considerar que su significado se encuentra asociado a que las personas puedan ver afectados sus derechos. La premisa en este texto es que las mujeres están expuestas en grados variables a sufrir violaciones en sus derechos fundamentales de: salud, educación y alimentación, así como en su libertad para ejercer derechos políticos y tener vidas seguras. La violencia conlleva restricciones al reconocimiento y al ejercicio de las capacidades para ejercer derechos políticos en condiciones de libertad e igualdad.

Así, en el concepto de violencia política se percibe que uno de sus componentes centrales es la idea de limitación del ejercicio de los derechos humanos. ${ }^{12}$ La Declaración sobre la Eliminación de la Violencia contra la Mujer reconoció desde 1993 el derecho de la mujer a vivir una vida libre de violencia. La Comisión Económica para América Latina y el Caribe (1996) estableció que la violencia hacia las mujeres era un asunto de violación de derechos e instó a los países de la región a tomar medidas para garantizarlos, así como a instaurar políticas que promuevan la protección de las víctimas. En México se dieron pasos significativos para asegurar la igualdad de derechos: destacan las reformas al texto constitucional en 2011, las cuales modificaron las formas de proteger los derechos humanos de todas las personas; la reforma en materia político-electoral de 2014 estableció en la Carta Magna los principios de equidad y paridad en los procesos político-electorales; y especialmente el decreto de $2020,{ }^{13}$ que incluyó un capítulo especial destinado a definir y tipificar la violencia política. Resulta importante reiterar que integrar la visión de la afectación a los derechos humanos de las mujeres representa un avance notable en la evolución del concepto, ya que éste no se circunscribe solamente a la agresión individual, sino se abre hacia las acciones que limitan la libertad y las posibilidades de ser como una afectación social y colectiva.

12 Se ha optado por utilizar el término derechos humanos, porque los derechos humanos son de carácter universal, y se considera que en su dimensión están incluidas las acepciones: derechos fundamentales, derechos cívicos, derechos politicos, derechos sociales, que algunos estudios restringen a ordenamientos jurídicos específicos (Carbonell, 2012).

13 El Decreto del Congreso General (DOF, 2020) establece reformas y adiciones, entre otros ordenamientos, a la Ley General de Acceso de las Mujeres a una Vida Libre de Violencia, a la Ley General de Instituciones y Procedimientos Electorales y a la Ley General de Partidos políticos. Y a otros ordenamientos vinculados a la definición y tipificación de la Violencia Politica contra las Mujeres en Razón de Género. 


\section{La perspectiva de la cultura}

Otro eje central del concepto de violencia política la asocia a patrones culturales arraigados en las sociedades; Beramendi et al. (2015: 55) advierte que "la violencia contra las mujeres es producto de una cultura que diagrama relaciones de poder y subordinación entre varones y mujeres". Para Cerva (2014: 4), la violencia en razón de género "es consecuencia de la desigualdad entre los géneros y se expresa en discriminación, diferentes oportunidades y responsabilidades en el acceso y control de recursos sustentada en la noción sociocultural de lo masculino como superior a lo femenino". Para Adrián (2015:17), el género es una construcción social que involucra estereotipos asociados al sexo y que se encuentran anclados a manifestaciones culturales.

\section{La perspectiva normativa}

Desde la óptica normativa se aportan análisis de marcos y definiciones legales a la construcción social de la noción de la violencia política en razón de género. Tales principios formulados como prescripciones jurídicas se han incorporado a los derechos electorales existentes a modo de códigos o protocolos de registro ante actos de violencia política, para identificar casos y acciones sancionables. Es pertinente notar que integrar la noción a los preceptos jurídicos ha permitido vincular el discurso internacional sobre los derechos de las mujeres con las particularidades de los Estados nacionales, avanzando en la precisión del concepto.

Otro punto destacable estriba en considerar que son las normas formales y las informales las que capturan las expresiones del fenómeno, a través de la forma que asumen los arreglos institucionales entre las estructuras del gobierno, los partidos y las relaciones entre los actores que compiten, conformando esquemas de inclusión o exclusión para sectores, grupos o individuos participantes.

La revisión de los textos enmarcados en esta perspectiva muestra que frecuentemente los marcos que en las legislaciones nacionales promueven la incorporación de mujeres en la vida política no la previenen ni sancionan, ya que ante las acciones afirmativas previstas para alcanzar mayor equidad, los actores y partidos políticos reaccionan negativamente (Castro, 2017; Saldaña, 2017; Hernández, 2017); condiciones en las cuales la no sanción y la propia violencia pueden ser vistas como tácticas para impedir la participación política de las mujeres (Krook, 2017; Krook y Restrepo, 2016a). Esto deriva en que las acciones afirmativas, como las leyes de cuotas, 
no ayuden a mantener la esfera política como un campo de juego neutral, sino como uno donde hay resistencias y reacciones violentas (Krook, 2015; Krook y Restrepo, 2016b).

\section{Los ejes sustantivos del concepto}

Si bien los apartados anteriores destacan las perspectivas conceptuales y vías que son centrales en el concepto de violencia política en razón de género, vale la pena reflexionar sobre algunas de las ideas sin las cuales resulta difícil dilucidar qué se entiende por violencia política. La primera de ellas conduce a señalar su naturaleza de acciones lesivas para las mujeres, que se configuran como obstáculos para el libre ejercicio de sus derechos políticos. Así, el nexo entre la noción de violencia y la idea de afectación a derechos es consustancial a su definición.

Otra premisa discurre en su apropiación como procesos de transferencia de los patrones de desigualdad, injusticia y discriminación hacia las mujeres, que están presentes en los patrones culturales de las sociedades y que se extienden a su participación en la política. Este presupuesto adscribe a la violencia política en razón de género un cierto carácter estructural, del cual forma parte un proceso de naturalización que dificulta su identificación, precisión y sanción. Se advierte que si bien no se pretende acceder a una definición general, sí resulta indispensable avanzar en líneas conceptuales básicas que permitan examinarla y medirla. En ese sentido, el eje de la reflexión descansa en que se reconocen las diferencias culturales en los roles de participación, pero se privilegian los principios de igualdad y justicia sobre las diferencias.

Finalmente, la reflexión conduce a aceptar que en la construcción social de la noción de violencia política hay componentes normativos insertos en el discurso internacional sobre los derechos humanos, componentes culturales, componentes derivados de la difusión de la perspectiva de género y el empoderamiento de las mujeres, y componentes derivados de entornos particulares en los cuales tiene lugar la participación política de las mujeres.

\section{Las lecturas de la noción de violencia política en la academia en México}

Se ha expresado que la violencia política en razón de género es un fenómeno recientemente visibilizado en los países latinoamericanos; en el contexto mexicano, buena parte de la literatura académica registra que los casos de este tipo de violencia han estado presentes desde hace tiempo, pero al igual que 
otras formas de violencia se han naturalizado, y la incorporación en mayor escala de las mujeres en la esfera política ha permitido que el fenómeno sea percibido en la vida pública (Vargas y Palazuelos, 2019; Alanís, 2017; Saldaña, 2017; Hernández, 2017). Para visibilizar la construcción social del concepto, en esta sección se analiza la literatura comprendida en el periodo 2013-2020, a partir de los componentes centrales ya identificados.

La óptica normativa resulta predominante y caracteriza la mayor parte de los textos; algunos resaltan las paradojas que enfrentan las mujeres que incursionan en la política en México (De Dios, 2017). Se habla de equidad de género mientras que en la práctica las mujeres enfrentan escenarios desiguales con obstáculos para ejercer sus derechos políticos. A modo de ejemplo, el Instituto Nacional Electoral (INE, 2015) analizó el registro paritario de candidaturas en la contienda electoral 2014-2015 a nivel federal, con un apartado dedicado a examinar el caso de las "Juanitas", como expresión de violencia política y como evidencia de la diversidad de obstáculos para impedir la participación política de las mujeres y simular el cumplimiento de la ley.

Torres (2016) revisó el marco normativo que promovió la paridad y la implementación de cuotas, y examinó la violencia política en contra de las candidatas en Chiapas durante la contienda electoral 2015. Por su parte, Hevia (2015) realizó un recuento de los derechos políticos de las mujeres en México y de las reformas legales que han hecho posible incrementar su presencia en la política; también revisó las reformas a la legislación electoral en los últimos 25 años y las analizó a partir de las recomendaciones de los organismos internacionales, declaraciones, acuerdos, asambleas, conferencias internacionales y movimientos feministas que impulsaron alianzas, acuerdos y pactos para promover una mayor participación política. Hevia (2015) concluye que pese a la aplicación de las cuotas, la participación y representación política de las mujeres, éstas se ven constantemente obstaculizadas por el acoso político. El estudio de Alanís (2017) aborda conceptualmente la violencia política y plantea las obligaciones de las autoridades jurisdiccionales frente a ella. Asimismo, hace una revisión documental de las leyes internacionales y nacionales que protegen los derechos políticos de las mujeres, así como de las reformas al INE en materia electoral. Su aportación es señalar la carencia de una ley que la tipifique y castigue, lo cual va en detrimento de la democracia y del proyecto de país.

Otras investigaciones se centran en su conceptualización legal (Álvarez, 2017), en la aplicación de las reformas político-electorales que han posibilitado una mayor participación de las mujeres en política (Saldaña, 
2017), y en la necesidad de legislar efectivamente para erradicarla considerando la multidimensionalidad del fenómeno (Hernández, 2017).

Un estudio cualitativo que emplea perspectiva de género y observación participante fue el llevado a cabo por la Universidad Autónoma de Chiapas (UNACH, 2018), en donde se recopiló evidencia empírica sobre la violencia política de género en el proceso electoral de 2017-2018 en el sureste de México: Chiapas, Tabasco, Campeche, Quintana Roo y Yucatán. En dicho estudio se realizaron entrevistas a operadores del sistema electoral, y también un análisis de la legislación local para cada caso. Los resultados mostraron que: la violencia política de género no es visible cuantitativamente en los sistemas de información institucionales, pero presenta situaciones alarmantes. Los estados de la región sureste del país han sido pioneros en impulsar los derechos políticos de las mujeres. En la región, las que ocupan un cargo público lo hacen en condiciones desiguales respecto a los hombres. Se reportan pocos casos de violencia de género denunciados ante las fiscalías locales y se señala que requieren especial atención las mujeres indígenas, un sector vulnerable que participa en estos procesos. En el estudio de la Universidad Autónoma de Chiapas (UNACH, 2018) se afirma que la mayoría de los casos de violencia política se dan en el ámbito municipal, y que son los presidentes y síndicos quienes ejercen violencia política en contra de las mujeres.

A estos esfuerzos de entendimiento se agrega que con el fin de promover los liderazgos femeninos y contribuir a la democracia paritaria en Colima, el Tribunal Electoral del Poder Judicial de la Federación y ONU Mujeres (2017) publicaron una ficha para describir la situación de la violencia política en relación con la participación de la mujer y la paridad de género; y que en el Estado de México, el Observatorio de Participación Política de las Mujeres en el Estado de México (2019) elaboró una guía de atención para estos casos. En esta entidad se publicaron también Protocolos para la Atención de la Violencia Política en Razón de Género, como una medida de emergencia mientras se espera la aprobación de las reformas legislativas para brindar la atención, sanción y reparación integral del daño causado a las mujeres. Los Protocolos recurren a diferentes fuentes nacionales e internacionales y a la jurisprudencia 48/2016, emitida por el Tribunal Electoral del Poder Judicial de la Federación. Durante 2019, la Cámara de Diputados publicó un documento con las iniciativas recibidas sobre violencia de género, que buscan tipificarla (Cámara de Diputados, 2019), y el manual Violencia politica en razón de género, con el objetivo de prevenirla (CELIG, 2020).

Un rasgo común en esas lecturas es el señalamiento de que las medidas de paridad y su establecimiento en la legislación mexicana han permitido 
avances significativos para incrementar la participación política de las mujeres, pero no resultan suficientes para impedir procesos de exclusión, discriminación y violencia que enfrentan las mujeres políticas. La existencia de protocolos no logra prevenirla ni erradicarla; por lo tanto, es indispensable establecer reglas claras para sancionarla.

La reflexión sobre el significado de la violencia política en la perspectiva normativa permite verla como acciones discriminatorias o malos usos del poder político en detrimento de las mujeres; marco en el cual la violencia sería ejercida por instituciones electorales deficientes, partidos políticos o instancias de representación política o de gobierno que no cumplen las normas.

Desde la perspectiva de los derechos humanos se ha realizado en México una serie de estudios centrados en mostrar cómo y por qué la violencia política contra las mujeres atenta contra la igualdad entre mujeres y hombres, y representa obstáculos para la democracia. Entre dichos estudios se encuentran los de Freidenberg (2017b: 19), que buscan conocer y visibilizar los problemas más comunes que enfrentan las mujeres "que hacen política en América Latina: el acoso y la violencia política”. Su método es el estudio de caso, para analizar experiencias comparadas en México y Bolivia. Freidenberg y Osornio (2017: 275) examinan también "las consecuencias inesperadas de los esfuerzos por mejorar el nivel de participación y representación política en México". Para ello analizan casos de violencia política en diversas entidades del país a partir de fuentes secundarias de información (notas periodísticas). El estudio pone de manifiesto que a mayor participación política de las mujeres en cargos no simbólicos, es decir, con capacidad real para tomar decisiones, mayor es la violencia política en contra de ellas. En 2018, la CNDH (2018) publicó un protocolo para atender la violencia política en razón de género como una herramienta dirigida a los partidos políticos, organizaciones sociales, grupos de mujeres y defensores de los derechos humanos, con el fin de fomentar la participación ciudadana, la cultura de la denuncia y una mayor justicia para las mujeres (CNDH, 2018).

En este rubro se inscribe también la evaluación de la incidencia de la violencia política en el proceso electoral 2017-2018 del Instituto Electoral de la Ciudad de México, que se realizó con un enfoque transversal de género, enunciando la necesidad de reconocer, respetar y proteger de forma efectiva los derechos humanos de todas las personas, como un requisito fundamental para la construcción de una sociedad democrática. Entre sus aportaciones está distinguir tres dimensiones de la violencia política: 1) violencia hacia las mujeres en política, como conductas de violencia y delitos en el contexto 
político que aparentemente no tienen un sesgo discriminatorio por género; 2) violencia política contra las mujeres, que se presenta en el contexto de la actividad política y busca coartar los derechos políticos de las mujeres, a quienes les afecta de forma directa o indirecta (a sus familiares y colaboradores); 3) violencia política de género o en razón de género, la cual se presenta cuando se afectan los derechos políticos de una mujer, y la conducta violenta tiene rasgos de discriminación por género (IECM, 2019:20). Uno de sus hallazgos es la alta incidencia de actos de violencia contra mujeres y hombres registrada en la Ciudad de México en el proceso electoral 2017-2018, sobre todo entre candidatas y precandidatas. Los resultados de dicha evaluación muestran que la mayor parte de ellas no fueron electas. Una lectura distinta en la perspectiva de derechos humanos es el libro de Vargas y Palazuelos (2019), que describe la lucha sistemática de las mujeres políticas en México para vencer los obstáculos que impiden su acceso y permanencia en puestos públicos. En la obra se discute la participación política de las mujeres, en relación con la desigualdad estructural que históricamente padecen y la violencia que obstaculiza el ejercicio de sus derechos político-electorales.

Finalmente se encuentran los estudios que toman como eje la perspectiva cultural y que consideran aspectos como la cultura política, el machismo, los derechos políticos de los pueblos originarios y los medios de comunicación como perpetradores de la violencia. Entre ellos, Cerva (2014) observó que las mujeres carecían de capital político y de trayectoria como militantes; por lo tanto, en caso de ser electas era más fácil que los varones se apropiaran de sus candidaturas, o que fueran enviadas a distritos electorales que se estimaban perdidos. Cerva (2014) señala que a pesar de los avances en materia legislativa existen reacciones negativas en los partidos políticos a aceptar las leyes de cuotas, lo cual genera un ambiente político hostil para las mujeres. Sus hallazgos se sustentan en el seguimiento de los datos de la elección federal de 2012, complementados con entrevistas a profundidad. Los resultados muestran que para el cumplimiento de la cuota de género se configuraron procesos de violencia política en la:

conformación de las listas, asimismo, durante la campaña (concretamente en los apoyos que les proporcionan los partidos en términos de financiamiento y protección; así como en el acompañamiento del partido y en el abandono de la estructura partidista a la hora de contar los votos (Cerva, 2014: 15).

Cerva (2014) indica que una vez electas se les integra en comisiones secundarias, con temas poco importantes, o en las tradicionalmente femeninas; todo esto tiene lugar en términos de una cultura política particular. 
Lagunes (2014) describe las situaciones que viven las mujeres que incursionan en el mundo público y las barreras que les impiden gozar plenamente de sus derechos políticos. Su análisis es etnográfico, entrevista a mujeres políticas, y da voz a quienes a lo largo de su trayectoria han sufrido violencia y que ocupaban cargos públicos al ser entrevistadas. Las situaciones de vulneración descritas van desde la violencia verbal (insultos, descalificaciones, calumnias, descrédito, falta de escucha) hasta golpes y exclusión. Lagunes (2014) afirma que la violencia política en razón de género no es un tema nuevo, pero sí uno del cual se habla poco, porque ninguna mujer política quiere pasar por víctima.

Narcía (2017) trata la cuestión de la violencia politica en razón de género en contenidos mediáticos con una muestra de cuatro entidades federativas: Oaxaca, Chiapas, Estado de México y Veracruz, ya que realizaron elecciones en 2014 y 2017, y a que fueron implementadas en 2014 las reformas políticoelectorales que establecieron el principio de paridad. Narcía (2017) examina la forma en que los medios de comunicación pueden ser utilizados para perpetrar violencia política de género. Sus resultados muestran que contribuyen a la violencia política al usar un lenguaje discriminatorio, sexista y no incluyente, al negarles el derecho de réplica, o al difundir estereotipos de género, escándalos de tipo sexual o privilegiar hablar de la vida íntima por sobre el desempeño profesional, también porque se destina a las mujeres menos tiempo aire en radio o televisión. La estrategia de Narcía (2017) consistió en revisar contenidos en medios de prensa y redes sociales como Facebook y Twitter, analizar notas periodísticas, y en realizar entrevistas a víctimas de violencia política, reporteros y periodistas.

Castro (2017) reflexiona sobre el proceso de aplicación de la paridad en las candidaturas para cargos de elección popular en Chiapas durante el proceso electoral 2014-2015. Señala que la mayor presencia de mujeres en escaños públicos tiene un impacto simbólico-político para las instituciones, advierte que la cultura política local se ve alterada y que se trastoca el monopolio político de los hombres. Espejel y Díaz (2017) abordan la violencia contra las mujeres en política realizando una investigación descriptiva y cualitativa que aporta evidencia empírica. Plantean que este tipo de violencia debilita los derechos políticos de las mujeres y muestra la persistencia de la desigualdad entre mujeres y hombres. Sus hallazgos denotan que la paridad en nuestro país ha permitido el incremento de la participación política de mujeres, pero ha dado lugar a distintos tipos de violencia, debido al vacío legal que hay para prevenirla, erradicarla y sancionarla. 
Finalmente, López (2017) reflexiona sobre la violencia política desde una óptica que considera los usos y costumbres de las comunidades y pueblos originarios. Documenta diversos casos de violencia política en mujeres de Oaxaca, así como los obstáculos y dificultades en el acceso a la justicia para las indígenas. Su análisis expone la insensibilidad de actores políticos e instituciones al obstaculizar que las mujeres indígenas ejerzan plenamente sus derechos.

En el eje que considera la relación entre la violencia política y el empoderamiento de las mujeres, Tagle (2017: 202) sitúa su reflexión en los esfuerzos que se han realizado en México para garantizar el ejercicio de "los derechos políticos de las mujeres a lo largo de la historia”, y sobre las faltas en asegurar su ejercicio pleno, al revisar lo acontecido con las medidas de paridad en fechas recientes. Apunta que el pleno derecho implicaría otro tipo de relaciones y otras formas de ejercer el poder entre mujeres y hombres, así como un nuevo tipo de instituciones y una nueva cultura política.

Fernández (2014) analiza desde la mirada ciudadana las candidaturas en las elecciones federales de 2012 en México, y encuentra que está permeada por estereotipos de género y prejuicios, lo cual incide en alguna medida en la violencia hacia las mujeres políticas; también muestra las desventajas que enfrentan las candidatas de acuerdo con la opinión de los votantes. Por su parte, Mejía y Flores (2016) aplican el enfoque de género al análisis de las elecciones de 2015 y examinan el proceso de selección de candidaturas en los partidos, la selección de distritos y delegaciones históricamente perdedores, y dan seguimiento a los candidatos electos en la Ciudad de México. Sus resultados indican que la paridad no se logró.

Mena et al. (2017: 98) reflexionan sobre las "manifestaciones de la violencia política en las contiendas electorales de 2015 en Chiapas”, mediante un estudio cualitativo con información de fuentes poco usuales en la investigación social, ya que retoman relatos de violencia a través de redes sociales, notas periodísticas y motores de búsqueda en Internet. Sus resultados muestran que la simulación de los partidos políticos en el cumplimiento de la ley de paridad de género reproduce y acentúa la desigualdad en la política formal, y genera nuevas formas de violencia hacia las mujeres. Mena et al. (2017) explican que la violencia política de género es un mecanismo sistemático que operacionaliza la anulación de la participación política de las mujeres. 


\section{Marcas y significados en el mapa de las lecturas}

Una marca significativa en las lecturas denota que en la última década se incrementaron en México los estudios sobre violencia politica en razón de género, especialmente después de la reforma político-electoral de 2014, y posteriormente a las elecciones federales de 2018 (véase Gráfica 2). Otra marca deja ver que la mayor parte de los estudios se centran en el marco normativo (39.1\%) y se orientan a definir legalmente el concepto; también señalan la necesidad de contar con protocolos adecuados y, en especial, con leyes que sancionen y promuevan su erradicación (véase Gráfica 3). Un hallazgo interesante en los textos publicados durante 2020 es que se trata de estudios cualitativos (21.9\%) que muestran la violencia política contra las mujeres localizada en territorios concretos e incorporan fuentes de información primaria, buscando recuperar testimonios de mujeres que han sido violentadas por incorporarse a la esfera política, aun cuando en su mayoría utilizan fuentes de información secundaria (68.8\%). Se observa, asimismo, entre las categorías conceptuales centrales para el examen de este campo, que adicionalmente a la violencia están las de participación política, paridad, cuotas de género y perspectiva de género, todas con diversas acepciones.

De modo general, los estudios en la perspectiva de los derechos humanos (17.2\% de la muestra) consideran que la violencia política en razón de género arremete contra el principio universal de respeto de los derechos, lo cual va en detrimento de la construcción democrática del país.

En la perspectiva cultural (17.2\% de la muestra), se destaca la complejidad de las relaciones que teje la violencia política en razón de género, inserta en los problemas estructurales de la desigualdad, discriminación, vulnerabilidad y otros componentes deslegitimadores que están presentes en las culturas políticas locales. En la perspectiva del empoderamiento $(14.1 \%$ de la muestra), la marca pone énfasis en cómo las mujeres políticas de nuestro país desafían reglas y normas tanto tácitas como explícitas propias del sistema que regula la esfera política; resaltan rasgos de liderazgo, aunque no niegan la existencia de la violencia. Finalmente, en las representaciones de la violencia política en la perspectiva de género (14.1\% de la muestra) se marca que en la cultura política predominan estereotipos, roles y sesgos de género, que impregnan las percepciones de los actores e instituciones y retroalimentan la existencia de la violencia política.

Marca significativa en todas las lecturas es la dispersión conceptual, pues se distinguieron diez maneras distintas de referirse a la violencia politica contra las mujeres por razones de género (véase Gráfica 4). 


\section{Conclusiones}

El recorrido por las lecturas sobre la violencia política en el ámbito académico en México, la expone como una noción que se reconfigura integrando otros conceptos centrales; simultáneamente se advierte su creciente importancia en los sectores políticos, pero se aprecia que no ha involucrado en sus repercusiones al resto de la sociedad; es decir, se la ubica como hechos negativos o anecdóticos que afectan a grupos específicos en los espacios políticos, por lo tanto, se les mira como ajenos en sus repercusiones en el ordenamiento social. La mirada general revela que una buena parte de los análisis ha sido construida por los organismos e instituciones que intervienen en los procesos electorales, por eso sus significados están vinculados a concepciones particulares de esos procesos, que no permiten capturar integralmente su naturaleza compleja.

En el conjunto de lecturas se percibe el carácter interno de lucha y competencia por el poder, las posiciones y las jerarquías en las instituciones, así como en las interacciones entre actores políticos, dejando fuera a otros espacios sociales que, sin duda, también juegan un papel relevante en los entramados que dan soporte y continuidad a las acciones de violencia política. Finalmente, se visibiliza que los intereses académicos están centrados en la descripción de los casos, y se basan en fuentes secundarias con notables vacíos en su entendimiento y explicación.

Un punto indispensable en la reflexión estriba en que la violencia política en razón de género, como otras violencias, se presenta en un continuo que va desde la violencia sutil hacia la extrema, lo cual dificulta su tipificación, definición y más aún la determinación de lo que puede y debe ser sancionable como forma específica.

Los rasgos mencionados dejan ver que la construcción conceptual de la violencia se ha inclinado más por el lado de la política procedimental que del lado de una visión integral y sustantiva; ello parece lógico en razón de que otras nociones con las que se le vincula son igualmente ambiguas y polisémicas. Eso significa que si existen dificultades en definir y medir el empoderamiento de las mujeres, o en explicar las brechas existentes entre hombres y mujeres en una sociedad, resulta todavía más difícil traducir esas nociones a un concepto o definición de violencia política en razón de género. 
Gloria Jovita Guadarrama Sánchez y Emma del Carmen Aguilar Pinto Las diversas lecturas del concepto de violencia politica en razón de género en México (2010-2020)

\section{Referencias}

ACNUDH (Oficina del Alto Comisionado de las Naciones Unidas para los Derechos Humanos) (2006), Los principales tratados internacionales de derechos bumanos, Estados Unidos: Naciones Unidas.

ACOBOL (Asociación de Concejalas Bolivianas) (2012), Acoso y violencia politica en razón de género afectan el trabajo político y gestión pública de las mujeres. Disponible en: https://acobol.org.bo/ [20 de marzo de 2020].

Adrián, Tamara (2015), "Visibilizando las formas invisibles de violencia de género", en Straka, Úrsula [coord.], Violencia de género, Venezuela: Universidad Católica Andrés Bello.

Alanís, María del Carmen (2017), "Violencia política hacia las mujeres. Respuesta del Estado ante la falta de una ley en México", en Freidenberg, Flavia y del Valle, Gabriela [eds.], Cuando hacer politica te cuesta la vida. Estrategias contra la violencia politica en América Latina, México: Universidad Nacional Autónoma de México, Instituto de Investigaciones Jurídicas y Tribunal Electoral de la Ciudad de México.

Albaine, Laura (2017), "Marcos normativos contra el acoso y/o violencia en razón de género en América Latina”, en Freidenberg, Flavia y del Valle, Gabriela [eds.], Cuando hacer politica te cuesta la vida. Estrategias contra la violencia politica en América Latina, México: Universidad Nacional Autónoma de México, Instituto de Investigaciones Jurídicas y Tribunal Electoral de la Ciudad de México.

Álvarez, Cheryl (2017), "Violencia política contra las mujeres en México", en Revista Mexiquense, México: Centro de Planeación Estratégica y Prospectiva Política. Disponible en: https://ceplan.com.mx/revista-mexiquenses-numeros/ [13 de marzo de 2020].

Astelarra, Judith (1990), "El espacio de la política”, en Astelarra, Judith [comp.], Participación politica de las mujeres, España: Siglo XXI.

Barrera, Dalia (2003), "Transgresiones, control social y violencia hacia las mujeres en el ámbito rural", en GenÉros, vol. 11, núm. 31, México: Universidad de Colima.

Barrera, Dalia [ed.] (2008), I Encuentro de Presidentas Municipales, Sindicas y Regidoras de los gobiernos municipales del estado de Guerrero, México: Grupo Interdisciplinario sobre Mujer, Trabajo y Pobreza y Secretaría de la Mujer del Gobierno del estado de Guerrero.

Barrera, Dalia (2011), Mujeres en el cabildo. Síndicas y regidoras veracruzanas, México: Grupo Interdisciplinario sobre Mujer, Trabajo y Pobreza.

Beramendi, Carmen et al. (2015), "Mirando las violencias contras las mujeres desde la perspectiva interseccional. Desafíos teóricos y metodológicos para su conceptualización y medición”, en Guajardo Soto, Gabriel y Rivera Viedma, Christian [eds.], Violencias contra las mujeres. Desafios y aprendizajes en la cooperación Sur-Sur, Chile: Facultad Latinoamericana de Ciencias Sociales.

Berger, Peter y Luckmann, Thomas (1967), La construcción social de la realidad, Argentina: Amorrortu.

Berger, Peter y Luckmann, Thomas (1997), Modernidad, pluralismo y crisis de sentido. La orientación del hombre moderno, México: Paidós.

Bermúdez, Flor Marina y Evangelista, Angélica (2018), "Referentes teórico-conceptuales en los estudios sobre género y violencia en México”, en Bermúdez Urbina, Flor Marina y 
Convergencia Revista de Ciencias Sociales, vol. 28, 2021, Universidad Autónoma del Estado de México

Evangelista García, Angélica [coords.], Espacios y Fronteras de la Violencia y el Género, México: El Colegio de la Frontera Sur, Universidad de Ciencias y Artes de Chiapas y Centro de Estudios Superiores de México y Centroamérica.

Bourdieu, Pierre y Wacquant, Loïc (2008), Una invitación a la sociología reflexiva, Argentina: Siglo XXI.

Brockmann, Erika (2017), "El acoso y la violencia en Bolivia: lecciones aprendidas", en Freidenberg, Flavia y del Valle, Gabriela [eds.], Cuando hacer politica te cuesta la vida.

Estrategias contra la violencia politica en América Latina, México: Universidad Nacional Autónoma de México, Instituto de Investigaciones Jurídicas y Tribunal Electoral de la Ciudad de México.

Butler, Judith (2004), Lenguaje, poder e identidad, España: Síntesis.

Calderón, Marco Antonio (1994), Violencia politica y elecciones municipales, México: El Colegio de Michoacán.

Cámara de Diputados (2019), Iniciativas sobre violencia politica de género, México: LXIII Legislatura, Cámara de Diputados.

Carbonell, Miguel (2012), Los derechos fundamentales en México, México: Porrúa y Universidad Nacional Autónoma de México.

Castro, Inés (2017), "Paridad y violencia política. Los retos de las mujeres indígenas de Chiapas", en Freidenberg, Flavia y del Valle, Gabriela [eds.], Cuando hacer politica te cuesta la vida. Estrategias contra la violencia politica en América Latina, México: Universidad Nacional Autónoma de México, Instituto de Investigaciones Jurídicas y Tribunal Electoral de la Ciudad de México.

Castro, Roberto (2012), "Problemas conceptuales en el estudio de la violencia de género. Controversias y debates a tomar en cuenta”, en Baca Tavira, Norma y Vélez Bautista, Graciela [coords.], Violencia de género y la desigualdad en el Estado de México, Argentina: Mnemosyne.

Castro, Roberto y Casique, Irene (2009), "Violencia de pareja contra las mujeres en México: una comparación entre encuestas recientes”, en Notas de Población, vol. 35, núm. 87, Chile: Comisión Económica para América Latina y el Caribe y Naciones Unidas.

Castro, Roberto y Riquer, Florinda (2003), "La investigación sobre violencia contra las mujeres en América Latina: entre el empirismo ciego y la teoría sin datos”, en Cadernos de Saúde Pública, vol. 19, núm. 1, Brasil: Escola Nacional de Saúde Pública Sérgio Arouca.

CELIG (Centro de Estudios Legislativos para la Igualdad de Género) (2020), Violencia politica en razón de género, México: LXIV Legislatura, Cámara de Diputados.

Cerva, Daniela (2014), "Participación política y violencia de género en México", en Revista Mexicana de Ciencias Politicas y Sociales, vol. 59, núm. 222, México: Universidad Nacional Autónoma de México.

CNDH (Comisión Nacional de Derechos Humanos) (2018), Violencia politica contra las mujeres en razón de género, México: Fiscalía Especializada Para la Atención de Delitos Electorales, Instituto Nacional Electoral, Comisión Ejecutiva de Atención a Víctimas, Fiscalía Especial para los Delitos de Violencia contra las Mujeres y Trata de Personas e Instituto Nacional de las Mujeres.

Comisión Económica para América Latina y el Caribe (1996), Violencia de género. Un problema de derechos humanos, Chile: Comisión Económica para América Latina y el Caribe. 
Gloria Jovita Guadarrama Sánchez y Emma del Carmen Aguilar Pinto Las diversas lecturas del concepto de violencia politica en razón de género en México (2010-2020)

Conway, Jill et al. (1996), "El concepto de género”, en Lamas, Martha [comp.], El género, La construcción cultural de la diferencia sexual, México: Universidad Nacional Autónoma de México y Porrúa.

Cueva, Carla et al. (2017), "El acoso político hacia las candidatas en el proceso electoral regional peruano en 2014", en Freidenberg, Flavia y del Valle, Gabriela [eds.], Cuando hacer politica te cuesta la vida. Estrategias contra la violencia política en América Latina, México: Universidad Nacional Autónoma de México, Instituto de Investigaciones Jurídicas y Tribunal Electoral de la Ciudad de México.

De Barbieri, Teresita (2003), Género en el trabajo parlamentario: la Legislatura mexicana a finales del siglo XX, Argentina: Consejo Latinoamericano de Ciencias Sociales.

De Dios, Vania Citlalli (2017), “Violencia política contra las mujeres en México”, en Derechos Fundamentales a Debate, año 2017, núm. 3, México: Comisión Estatal de Derechos Humanos e Instituto de Investigación y Capacitación en Derechos Humanos.

Del Valle, Gabriela (2017), “ ¿Hacia dónde vamos? Construcción de una agenda para la erradicación de la violencia política contra las mujeres en América Latina”, en Freidenberg, Flavia y del Valle, Gabriela [eds.], Cuando hacer politica te cuesta la vida. Estrategias contra la violencia politica en América Latina, México: Universidad Nacional Autónoma de México, Instituto de Investigaciones Jurídicas y Tribunal Electoral de la Ciudad de México.

DOF (Diario Oficial de la Federación) (2020), Decreto por el que reforman y adicionan diversas disposiciones de la Ley General de Acceso de las Mujeres a una Vida Libre de Violencia, de La Ley General de Instituciones y Procedimientos Electorales, de la Ley General del Sistema de Impugnación en Materia Electoral, de la Ley General de Partidos Politicos, de la Ley General en Materia de Delitos Electorales, de la Ley Orgánica de la Fiscalia General de la República, de la Ley Orgánica del Poder Judicial de la Federación, y de la Ley General de Responsabilidades Administrativas, DOF: 13/04/2020, México: Secretaría de Gobernación.

Espejel, Alberto y Díaz, Mariela (2019), "Violencia contra las mujeres en política en México: una propuesta de análisis desde las caras partidistas”, en Apuntes Electorales, año VIII, núm. 60, México, Instituto Electoral del Estado de México.

Fernández, Dhayana (2015), “Mujeres con VIH y Violencia basada en Género”, en Straka, Úrsula [coord.], Violencia de género, Venezuela: Universidad Católica Andrés Bello.

Fernández, Anna María (2014), "Mujeres candidatas en la mira: percepciones y representaciones ciudadanas", en Revista Mexicana de Sociología, vol. 76, núm. 1, México: Universidad Nacional Autónoma de México.

Fernández, Patricia (2017), "Empoderamiento político de las mujeres: una estrategia integral para las políticas públicas”, en UNIVERSITAS. Revista de Filosofía, Derecho y Politica. DOI: 10.20318/universitas.2017.3750 Disponible en: https://e-revistas. uc3m.es/index.php/UNIV/article/view/3750/2353 [30 de marzo de 2020].

Freidenberg, Flavia (2018), Los retos institucionales y politicos para impulsar la democracia paritaria en Chiapas, México: Universidad Autónoma de Chiapas e Instituto de Elecciones y Participación Ciudadana Chiapas.

Freidenberg, Flavia (2017a), "La violencia política hacia las mujeres: el problema, los debates y las propuestas para América Latina”, en Freidenberg, Flavia y del Valle, Gabriela [eds.], Cuando hacer politica te cuesta la vida. Estrategias contra la violencia politica en América Latina, México: Universidad Nacional Autónoma de México, Instituto de 
Investigaciones Jurídicas y Tribunal Electoral de la Ciudad de México.

Freidenberg, Flavia [ed.] (2017b), La representación politica de las mujeres en México, México: Instituto Nacional Electoral, Instituto de Investigaciones Jurídicas y Universidad Nacional Autónoma de México.

Freidenberg, Flavia y Del Valle, Gabriela [eds.] (2017), Cuando hacer politica te cuesta la vida. Estrategias contra la violencia política en América Latina, México: Universidad Nacional Autónoma de México, Instituto de Investigaciones Jurídicas y Tribunal Electoral de la Ciudad de México.

Freidenberg, Flavia y Osornio, María Cristina (2017), "Las consecuencias inesperadas de la participación: la violencia política hacia las mujeres en México", en Freidenberg, Flavia [ed.], La representación política de las mujeres en México, México: Instituto Nacional Electoral, Instituto de Investigaciones Jurídicas y Universidad Nacional Autónoma de México.

Galtung, Johan (1969), "Violence, peace and peace research", en Journal of Peace Research, vol. 6, núm. 3, Noruega: Peace Research Institute.

García, Silvia (2014), "La violencia de género contra las mujeres en el espacio de la política. Un estado de la cuestión en América Latina", ponencia presentada en el XXXV Congreso Nacional y V Internacional de Estudios Electorales "Integridad y equidad electoral en América Latina”, noviembre, San José, Costa Rica.

García, Virginia (2017), "De techos, suelos, laberintos y precipicios. Estereotipos de género, barreras y desafíos de las mujeres políticas", en Freidenberg, Flavia y del Valle, Gabriela [eds.], Cuando hacer politica te cuesta la vida. Estrategias contra la violencia politica en América Latina, México: Universidad Nacional Autónoma de México, Instituto de Investigaciones Jurídicas y Tribunal Electoral de la Ciudad de México.

González, María de Jesús (2009), "Las sufragistas británicas y la conquista del espacio público", en Arenal, vol. 16, núm. 1, España: Universidad de Granada.

Hernández, María del Pilar (2017), "Violencia política contra las mujeres: ¿̨leyes especiales o medidas multidimensionales", en Freidenberg, Flavia y del Valle, Gabriela [eds.], Cuando hacer politica te cuesta la vida. Estrategias contra la violencia política en América Latina, México: Universidad Nacional Autónoma de México, Instituto de Investigaciones Jurídicas y Tribunal Electoral de la Ciudad de México.

Hevia, Teresa (2015), "Evolución y establecimiento de cuotas en México y las implicaciones de la reforma político-electoral de 2014 en cuanto a la aplicación de la paridad de género en el registro de candidaturas para la integración de la Cámara de Diputados", en Impacto del Registro de candidaturas en el proceso electoral federal 2014-2015, México: Instituto Nacional Electoral.

IECM (Instituto Electoral de la Ciudad de México) (2019), Evaluación de la incidencia de la violencia politica contra las mujeres en el contexto del proceso electoral 2017-2018, en cumplimiento a la resolución de la Sala Superior del Tribunal Electoral del Poder Judicial de la Federación, recaida en el expediente del recurso de reconsideración identificado con la clave alfanumérica SUP-REC-1388/2018, México: Instituto Electoral de la Ciudad de México.

INE (Instituto Nacional Electoral) (2015), Impacto del registro paritario de candidaturas en el proceso electoral federal 2014-2015, México: Instituto Nacional Electoral. 
INE (Instituto Nacional Electoral) (2018), Protocolo para atender las medidas tendientes a garantizar a las personas trans el ejercicio del voto en igualdad de condiciones y sin discriminación en todos los tipos de elección y mecanismos de participación ciudadana, México: Instituto Nacional Electoral.

Krook, Mona Lena (2017), “¿Qué es la violencia política? El concepto desde la perspectiva de la teoría y la práctica”, en Freidenberg, Flavia y del Valle, Gabriela [eds.], Cuando hacer politica te cuesta la vida. Estrategias contra la violencia politica en América Latina, México: Universidad Nacional Autónoma de México, Instituto de Investigaciones Jurídicas y Tribunal Electoral de la Ciudad de México.

Krook, Mona Lena y Restrepo, Juliana (2016a), "Violencia contra las mujeres en política. En defensa del concepto”, en Politica y Gobierno, vol. 23, núm. 1, México: Centro de Investigación y Docencia Económicas.

Krook, Mona Lena y Restrepo, Juliana (2016b), "Género y violencia política en América Latina: Conceptos, debates y soluciones”, en Politica y Gobierno, vol. 23, núm. 2, México: Centro de Investigación y Docencia Económicas.

Krook, Mona Lena (2015), "Empowerment versus backlash: gender quotas and critical mass theory”, en Politics, Groups and Identities. DOI: 10.1080/21565503.2014.999806 Disponible en: https://www.tandfonline.com/doi/abs/10.1080/21565503.2014.99 9806 [30 de marzo de 2020].

Lagarde, Marcela (1996), Género y feminismo. Desarrollo humano y democracia, España: Horas y Horas.

Lagunes, Lucía (2014), “Mexicanas sobrevivientes del machismo”, en Hoyos, María Paula [ed.], Mujeres muy politicas. Mujeres muy públicas. Crónicas de acoso a mujeres politicas, Colombia: Friedrich Ebert Stiftung.

López, Rita Bell (2017), "Violencia política hacia las mujeres indígenas en los municipios de Oaxaca”, en Freidenberg, Flavia y del Valle, Gabriela [eds.], Cuando hacer politica te cuesta la vida. Estrategias contra la violencia politica en América Latina, México: Universidad Nacional Autónoma de México, Instituto de Investigaciones Jurídicas y Tribunal Electoral de la Ciudad de México.

Massolo, Alejandra (2007), Participación politica de las mujeres en el ámbito local en América Latina, Agencia Española de Cooperación Internacional, República Dominicana: UnInstraw Instituto Internacional de Investigaciones y Capacitación de las Naciones Unidas para la Promoción de la Mujer.

Mena, Ramón et al. (2017), "Manifestaciones de la violencia política de género en las contiendas electorales 2015 en Chiapas. Notas para el análisis", en Liminar. Estudios Sociales y Humanísticos, vol. 15, núm. 1, México: Universidad de Ciencias y Artes de Chiapas.

Mejía, Nancy y Flores, Brando (2016), Igualdad bajo el microscopio. Análisis de género en las elecciones 2015, México: Instituto de Liderazgo Simón de Beauvoir.

Millett, Kate (1971), Sexual Politics, Estados Unidos: Equinox.

Narcía, Elva (2017), Violencia política contra las mujeres en contenidos mediáticos, México: Glifos Comunicaciones.

Novo, Amparo (2010), “El camino hacia el empoderamiento político de las mujeres”, en Revista Estudos Feministas, vol. 18, núm. 3, Brasil: Universidade Federal de Santa Catarina. 
Convergencia Revista de Ciencias Sociales, vol. 28, 2021, Universidad Autónoma del Estado de México

Observatorio de Participación Política de las Mujeres en el Estado de México (2019), Guía de atención en casos de violencia politica contra las mujeres por razones de género en el Estado de México. Atribuciones y procedimientos, México: Consejo Estatal de la Mujer y Bienestar Social, Instituto Electoral del Estado de México y Tribunal Electoral del Estado de México.

OMS (Organización Mundial de la Salud) (2019), Violencia. Disponible en: https://www. who.int/topics/violence/es/ [24 de abril de 2019].

OPS (Organización Panamericana de la Salud) (2003), Informe mundial sobre violencia y salud, Estados Unidos: Oficina Regional para las Américas de la Organización Mundial de la Salud.

Otálora, Janine (2017), "Participación y violencia política contra las mujeres en América Latina: una evolución de marcos y prácticas”, en Freidenberg, Flavia y del Valle, Gabriela [eds.], Cuando hacer politica te cuesta la vida. Estrategias contra la violencia politica en América Latina, México: Universidad Nacional Autónoma de México, Instituto de Investigaciones Jurídicas y Tribunal Electoral de la Ciudad de México.

Pateman, Carole (1995), El contrato sexual, España: Anthropos y Universidad Autónoma Metropolitana-Iztapalapa.

Pereira, Carlos (1974), Política y violencia, México: Fondo de Cultura Económica.

Piscopo, Jenifer (2017), "Los riesgos de sobre legislar. Reflexiones acerca de las respuestas institucionales a la violencia contra las mujeres que hacen política en América Latina", en Freidenberg, Flavia y del Valle, Gabriela [eds.], Cuando hacer politica te cuesta la vida. Estrategias contra la violencia politica en América Latina, México: Universidad Nacional Autónoma de México, Instituto de Investigaciones Jurídicas y Tribunal Electoral de la Ciudad de México.

Quiñones, Adriana (2018), Si somos más de la mitad, ¿por qué no tenemos paridad?, Guatemala: Programa de las Naciones Unidas para el Desarrollo, International Institute for Democracy and Electoral Assistance y ONU Mujeres.

Rowlands, Joana (1997), "Empoderamiento y mujeres rurales en Honduras: un modelo para el desarrollo", en León, Margadalena [comp.], Poder y empoderamiento de las mujeres, Colombia: Tercer Mundo.

Saldaña, Lucero (2017), “Legislar: una herramienta para la erradicación de la violencia política contra las mujeres en México", en Freidenberg, Flavia y del Valle, Gabriela [eds.], Cuando hacer politica te cuesta la vida. Estrategias contra la violencia politica en América Latina, México: Universidad Nacional Autónoma de México, Instituto de Investigaciones Jurídicas y Tribunal Electoral de la Ciudad de México.

Sam, María Magdalena (2002), Mujer y gobierno municipal. Factores que ayudan o dificultan la participación femenina en los ayuntamientos de Tlaxcala, 1999-2001, México: Universidad Autónoma de Tlaxcala y Centro de Investigaciones Interdisciplinarias sobre Desarrollo Regional.

Sam, María Magdalena (2003), "Participación política de las mujeres en los ayuntamientos: el caso de Tlaxcala”, en Barrera Bassols, Dalia y Massolo, Alejandra [comps.], El municipio. Un reto para la igualdad de oportunidades entre hombres y mujeres, México: Instituto Nacional de las Mujeres y Grupo Interdisciplinario sobre Mujer, Trabajo y Pobreza.

Segato, Laura Rita (2003), Las estructuras elementales de la violencia. Ensayos sobre género entre la antropología, el psicoanálisis y los derechos bumanos, Argentina: Universidad Nacional de Quilmes. 
Scott, Joan (1996), "El género una categoría útil para el análisis histórico", en Lamas, Martha [comp.], El género, la construcción cultural de la diferencia sexual, México: Universidad Nacional Autónoma de México y Porrúa.

Tagle, Martha (2017), "Estrategias para romper los candados contra las mujeres 'De' y 'En' los partidos políticos en México", en Freidenberg, Flavia y del Valle, Gabriela [eds.], Cuando hacer politica te cuesta la vida. Estrategias contra la violencia politica en América Latina, México: Universidad Nacional Autónoma de México, Instituto de Investigaciones Jurídicas y Tribunal Electoral de la Ciudad de México.

Talancón, Jaime Hugo (2009), "Violencia política", en Revista de la Facultad de Derecho de México, vol. 59, núm. 251, México: Universidad Nacional Autónoma de México.

Tarrés, María Luisa (1998), “¿Importa el género en la política?”, en Tarrés Barraza, María Luisa [coord.], Género y Cultura en América Latina, México: El Colegio de México.

Tello, Pilar (2019), "Participación política de la mujer en América Latina y el Caribe: Avances, tendencias y desafíos", en Conferencia Regional sobre la Mujer de América Latina y el Caribe, Chile: Comisión Económica para América Latina y el Caribe. Disponible en: https://conferenciamujer.cepal.org/14/sites/crm14/files/11_participacion_politica_ de_la_mujer_en_lac.pdf [22 de marzo de 2020].

Torres, Eduardo (2016), "Violencia política en las elecciones subnacionales mexicanas. El caso de Chiapas en 2015", en Politai. Revista de Ciencia Politica, vol. 7, núm. 12, Perú: Pontificia Universidad Católica del Perú.

Tribunal Electoral del Poder Judicial de la Federación y ONU Mujeres (2017), Foros Regionales. Fortalecimiento de capacidades para la formación de liderazgos femeninos hacia la construcción de una democracia paritaria y libre de violencia. Participación politica electoral de las mujeres en el Estado de Colima, México: Tribunal Electoral del Poder Judicial y de la Federación y ONU Mujeres.

Universidad Autónoma de Chiapas (2018), Observación y seguimiento de la violencia politica contra las mujeres en la región sureste. Informe final, México: Universidad Autónoma de Chiapas.

Vargas, Gabriela y Palazuelos, Silvia (2019), Violencia politica contra las mujeres: el precio de la paridad en México, México: Yopublico.

Vázquez, Natalia Ix-chel y Díaz, Guillermina (2012), "Representaciones sociales de la mujer en la prensa del Estado de México", en Vélez Bautista, Graciela y Baca Tavira, Norma [comps.], Género y desigualdades en Iberoamérica, Argentina: Mnemosyne.

Yáñez, Raúl (2010), "La construcción social de la realidad. La posición de Peter L. Berger y Thomas Luckmann", en Ars Boni et Aequi, vol. 6, núm. 2, Chile: Universidad Bernardo O’Higgins. 


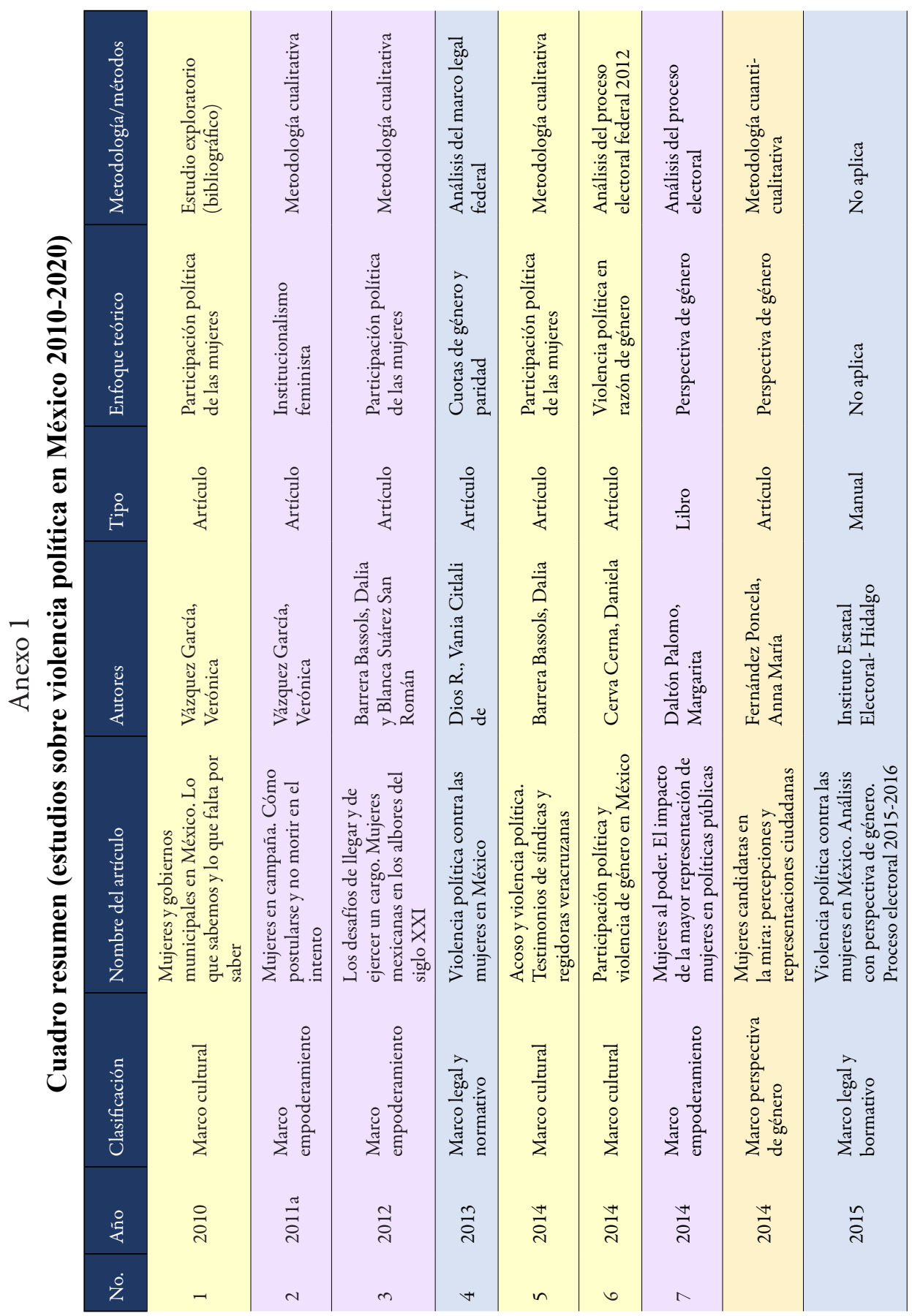


Gloria Jovita Guadarrama Sánchez y Emma del Carmen Aguilar Pinto

Las diversas lecturas del concepto de violencia politica en razón de género en México (2010-2020)

\begin{tabular}{|c|c|c|c|c|c|c|c|c|c|}
\hline 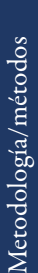 & 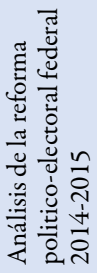 & 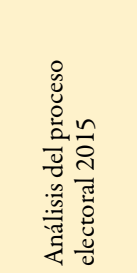 & 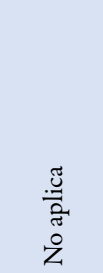 & 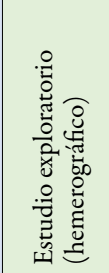 & 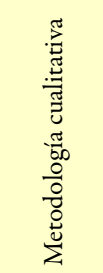 & 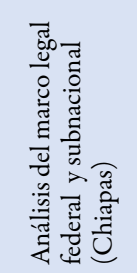 & 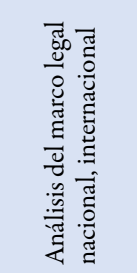 & 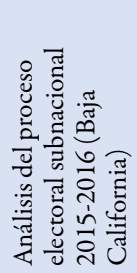 & 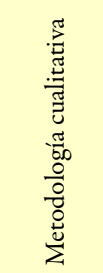 \\
\hline 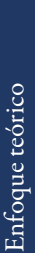 & 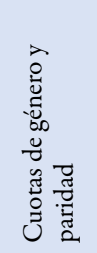 & 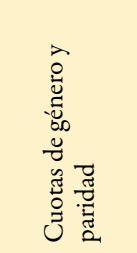 & 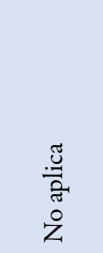 & 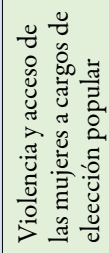 & 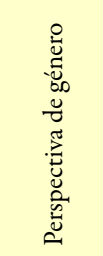 & 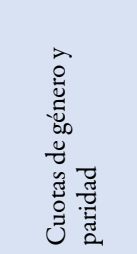 & 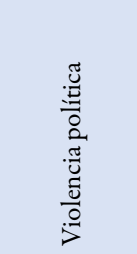 & 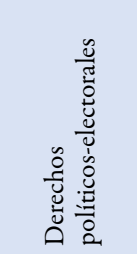 & 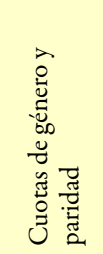 \\
\hline$\stackrel{2}{g}$ & 总 & $\stackrel{\circ}{\stackrel{\circ}{3}}$ & $\begin{array}{l}\text { 웅 } \\
\dot{0} \\
\stackrel{0}{0} \\
\stackrel{0}{0}\end{array}$ & 䓌 & 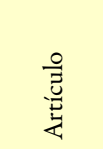 & $\frac{0}{3}$ & 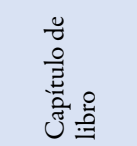 & $\begin{array}{l}0 \\
\text { 晜 } \\
\text { 茎 }\end{array}$ & 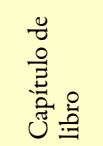 \\
\hline 总 & 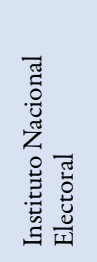 & 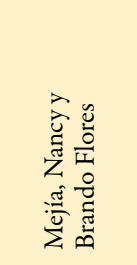 & 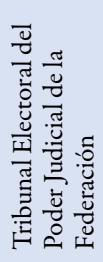 & 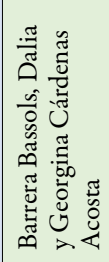 & 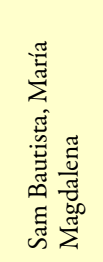 & 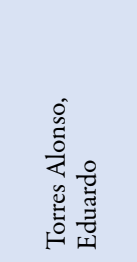 & 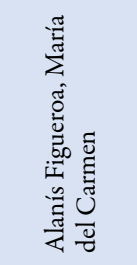 & 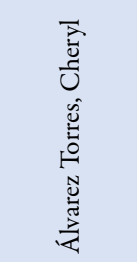 & 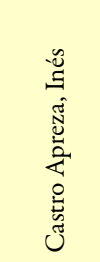 \\
\hline 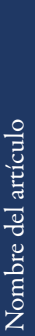 & 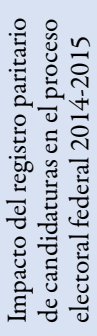 & 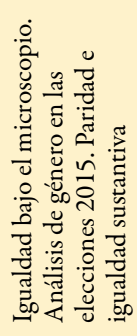 & 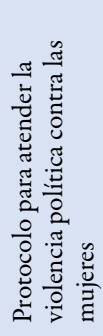 & 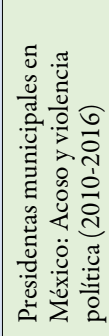 & 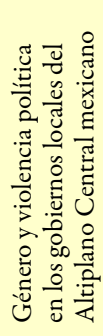 & 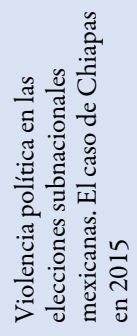 & 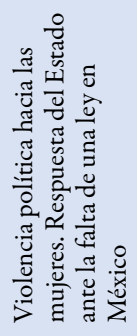 & 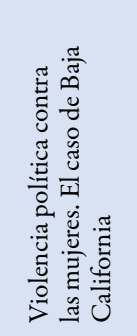 & 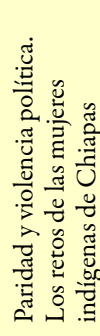 \\
\hline 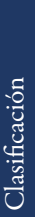 & 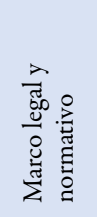 & 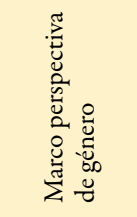 & 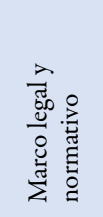 & 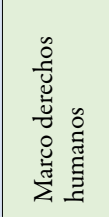 & 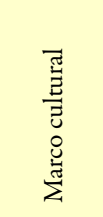 & 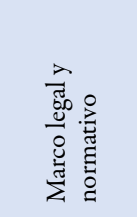 & 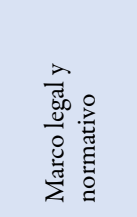 & 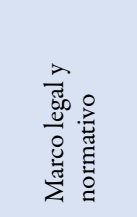 & 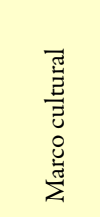 \\
\hline & $\frac{n}{\tilde{N}}$ & $\stackrel{n}{\tilde{\nu}}$ & 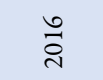 & 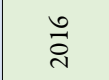 & $\stackrel{\circ}{\stackrel{\sim}{\pi}}$ & ֻั & $\overrightarrow{\widetilde{i}}$ & $\widehat{\widehat{i}}$ & $\widehat{\vec{i}}$ \\
\hline & & & & & & & & & \\
\hline
\end{tabular}


Convergencia Revista de Ciencias Sociales, vol. 28, 2021, Universidad Autónoma del Estado de México

\begin{tabular}{|c|c|c|c|c|c|c|c|c|c|}
\hline 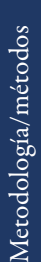 & 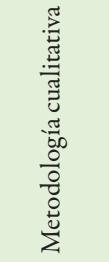 & 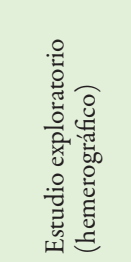 & 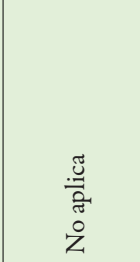 & 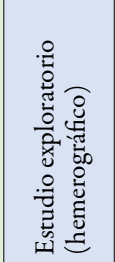 & 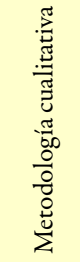 & 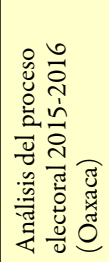 & 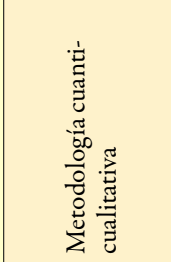 & 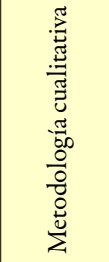 & 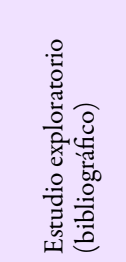 \\
\hline 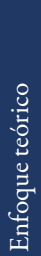 & 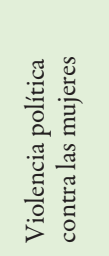 & 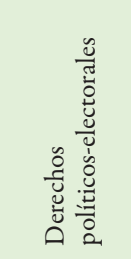 & 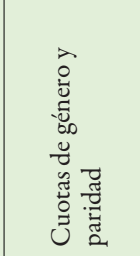 & 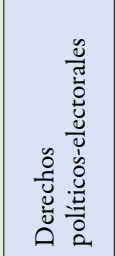 & 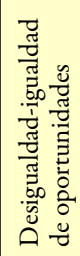 & 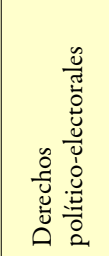 & 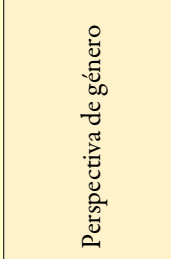 & 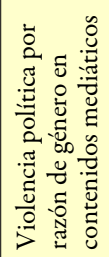 & 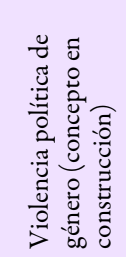 \\
\hline$\stackrel{\circ}{:}$ & 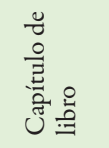 & 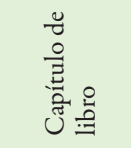 & 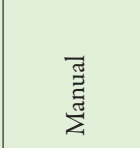 & 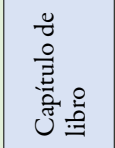 & 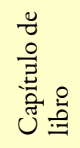 & 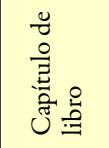 & $\frac{0}{\frac{0}{\tilde{E}}}$ & 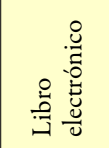 & 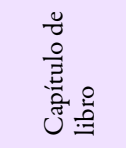 \\
\hline 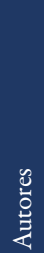 & 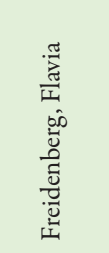 & 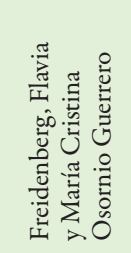 & 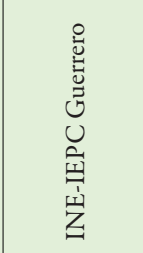 & 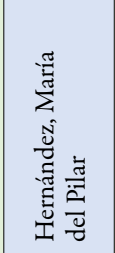 & 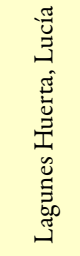 & 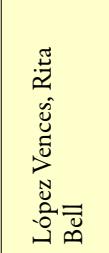 & 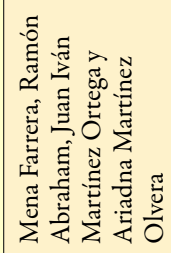 & 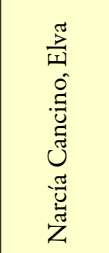 & 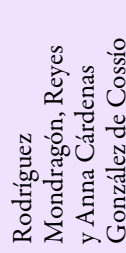 \\
\hline 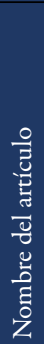 & 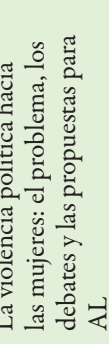 & 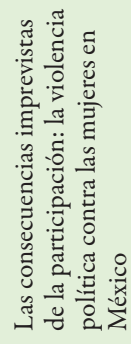 & 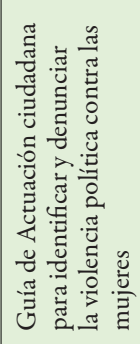 & 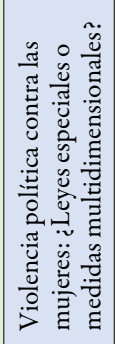 & 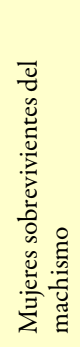 & 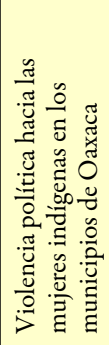 & 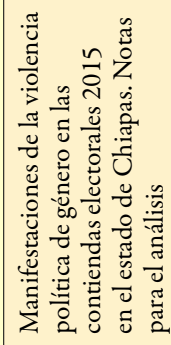 & 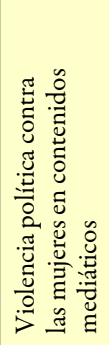 & 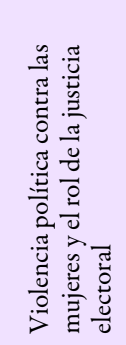 \\
\hline 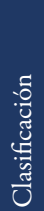 & 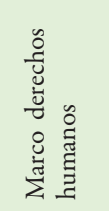 & 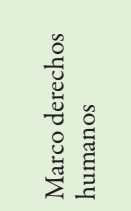 & 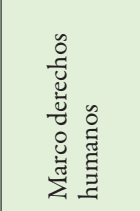 & 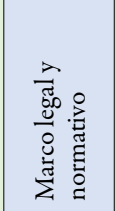 & 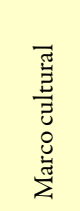 & 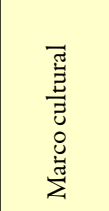 & 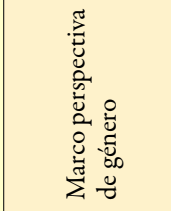 & 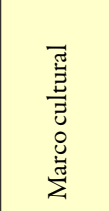 & 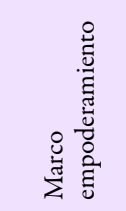 \\
\hline & $\overrightarrow{\vec{\sim}}$ & $\widehat{\vec{i}}$ & $\hat{\vec{N}}$ & 穴 & $\widehat{\vec{\Lambda}}$ & $\hat{\vec{N}}$ & $\stackrel{\widehat{ }}{\vec{i}}$ & $\overrightarrow{\widetilde{\sim}}$ & $\widehat{\vec{i}}$ \\
\hline & & & & & & & & & \\
\hline
\end{tabular}


Gloria Jovita Guadarrama Sánchez y Emma del Carmen Aguilar Pinto Las diversas lecturas del concepto de violencia politica en razón de género en México (2010-2020)

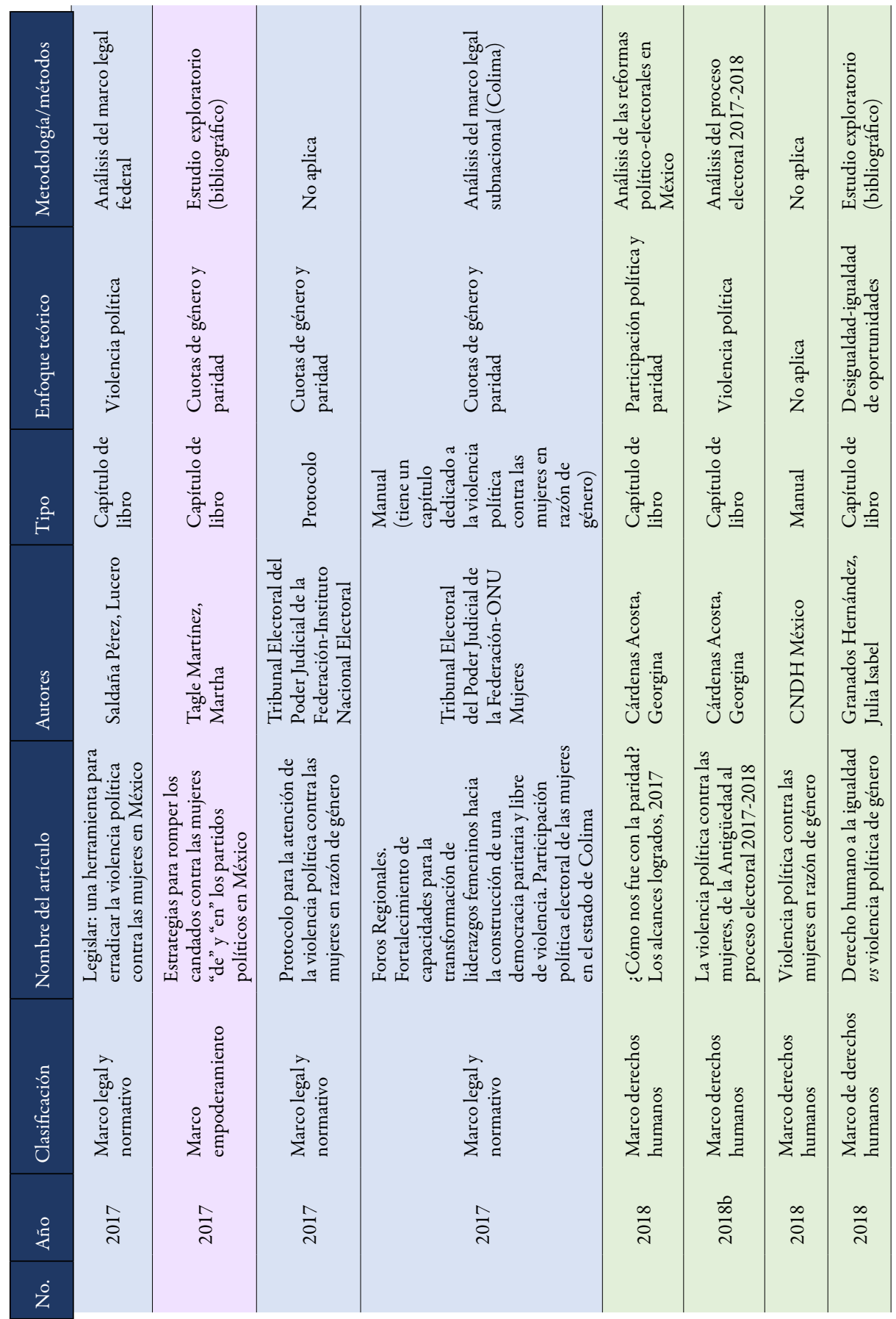




\begin{tabular}{|c|c|c|c|c|c|c|c|c|}
\hline 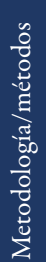 & 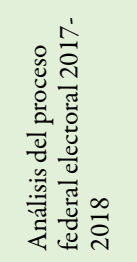 & 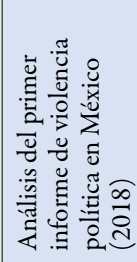 & 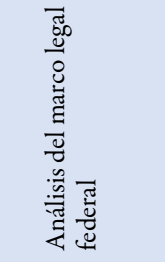 & 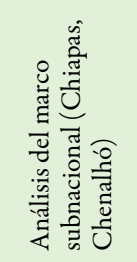 & 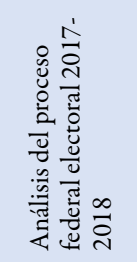 & 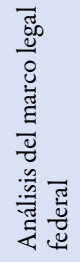 & 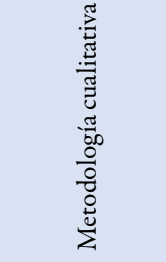 & 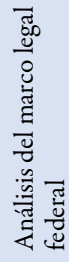 \\
\hline 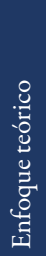 & 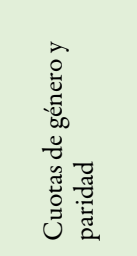 & 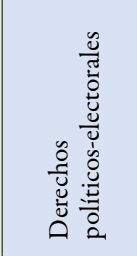 & 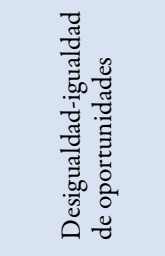 & 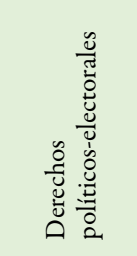 & 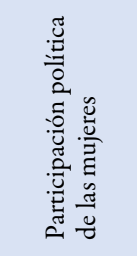 & 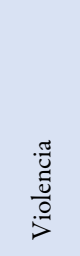 & 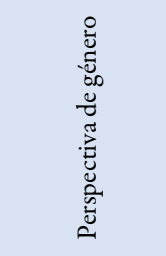 & 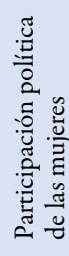 \\
\hline$\stackrel{\circ}{\stackrel{2}{\rightleftarrows}}$ & $\begin{array}{l}\frac{0}{\bar{Z}} \\
\text { 䓠 }\end{array}$ & 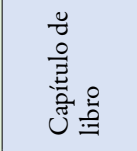 & 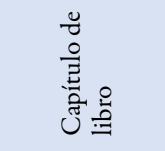 & $\frac{0}{\vec{Z}}$ & 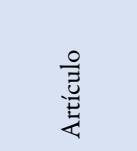 & 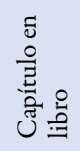 & 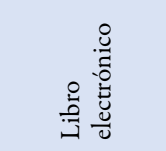 & 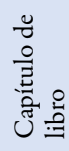 \\
\hline $\begin{array}{l}\stackrel{\circlearrowright}{0} \\
\stackrel{3}{4}\end{array}$ & 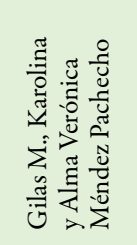 & 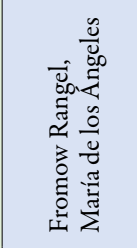 & 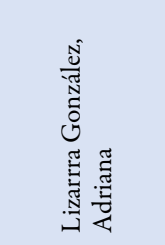 & 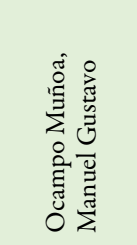 & 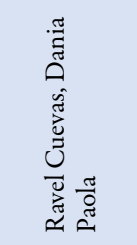 & 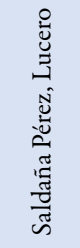 & 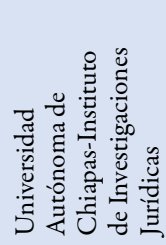 & 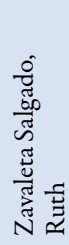 \\
\hline 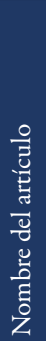 & 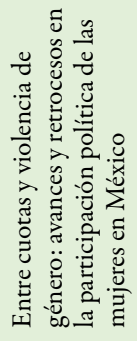 & 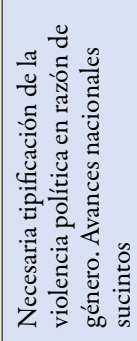 & 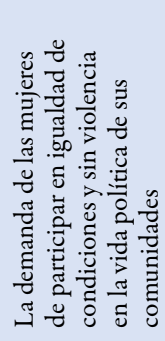 & 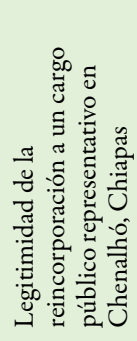 & 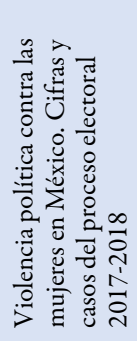 & 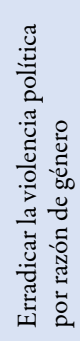 & 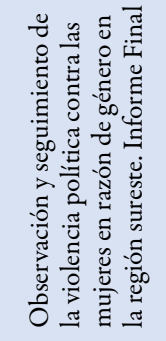 & 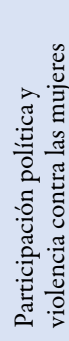 \\
\hline 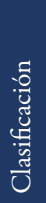 & 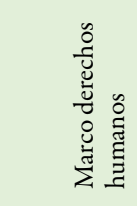 & 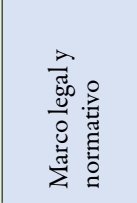 & 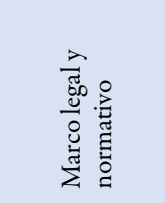 & 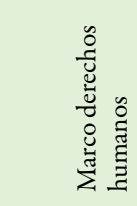 & 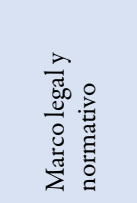 & 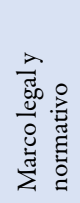 & 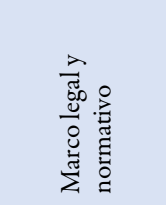 & 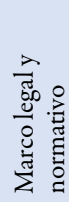 \\
\hline & $\stackrel{\infty}{\stackrel{\text { సे }}{~}}$ & $\stackrel{\infty}{\stackrel{\sim}{\sim}}$ & $\stackrel{\infty}{\stackrel{\sim}{\sim}}$ & $\stackrel{\infty}{\stackrel{\sim}{\sim}}$ & $\stackrel{\infty}{\vec{\sim}}$ & $\stackrel{\infty}{\stackrel{\infty}{\sim}}$ & $\stackrel{\infty}{\stackrel{\infty}{\sim}}$ & $\stackrel{\infty}{\stackrel{\infty}{*}}$ \\
\hline & & & & & & & & \\
\hline
\end{tabular}


Gloria Jovita Guadarrama Sánchez y Emma del Carmen Aguilar Pinto Las diversas lecturas del concepto de violencia politica en razón de género en México (2010-2020)

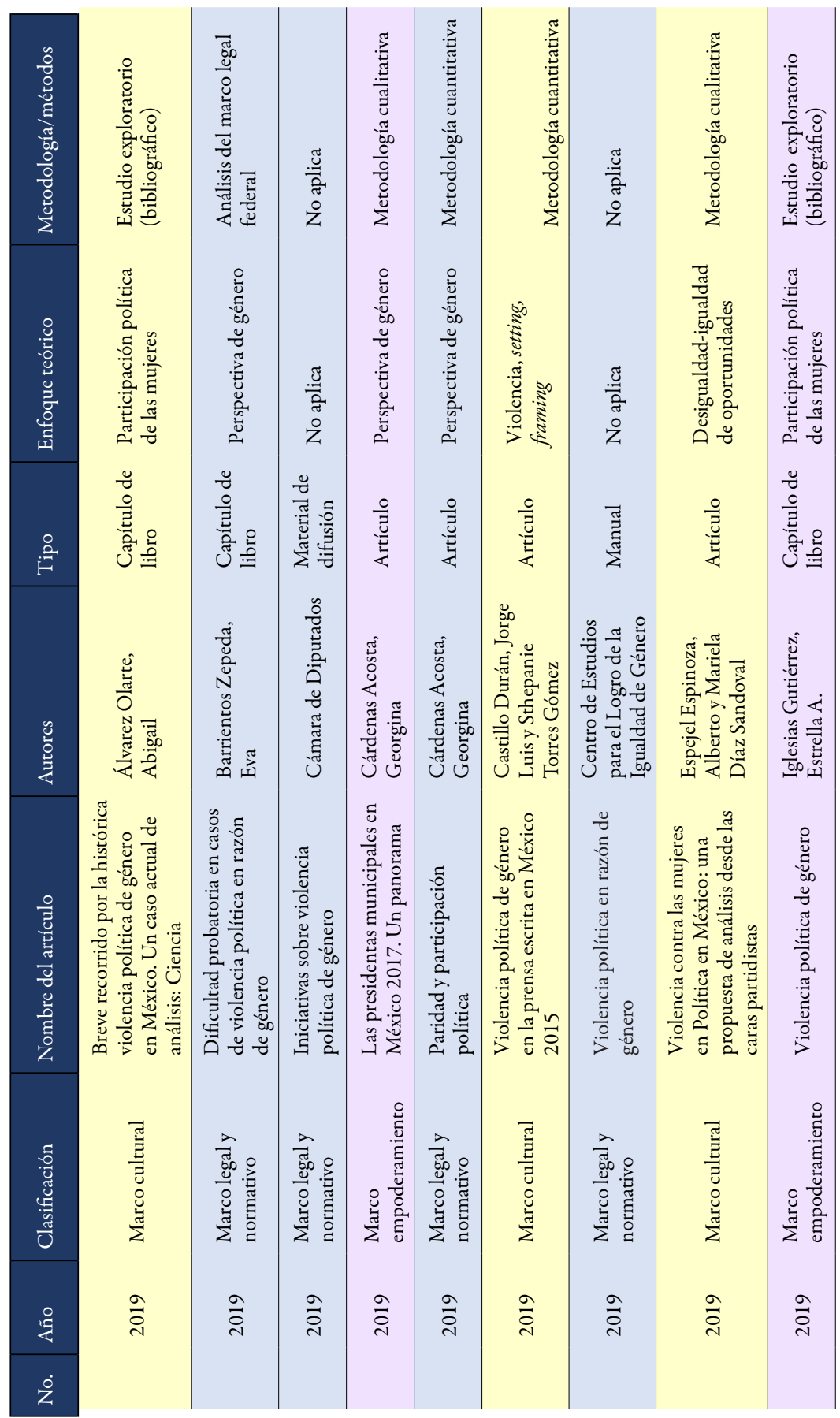




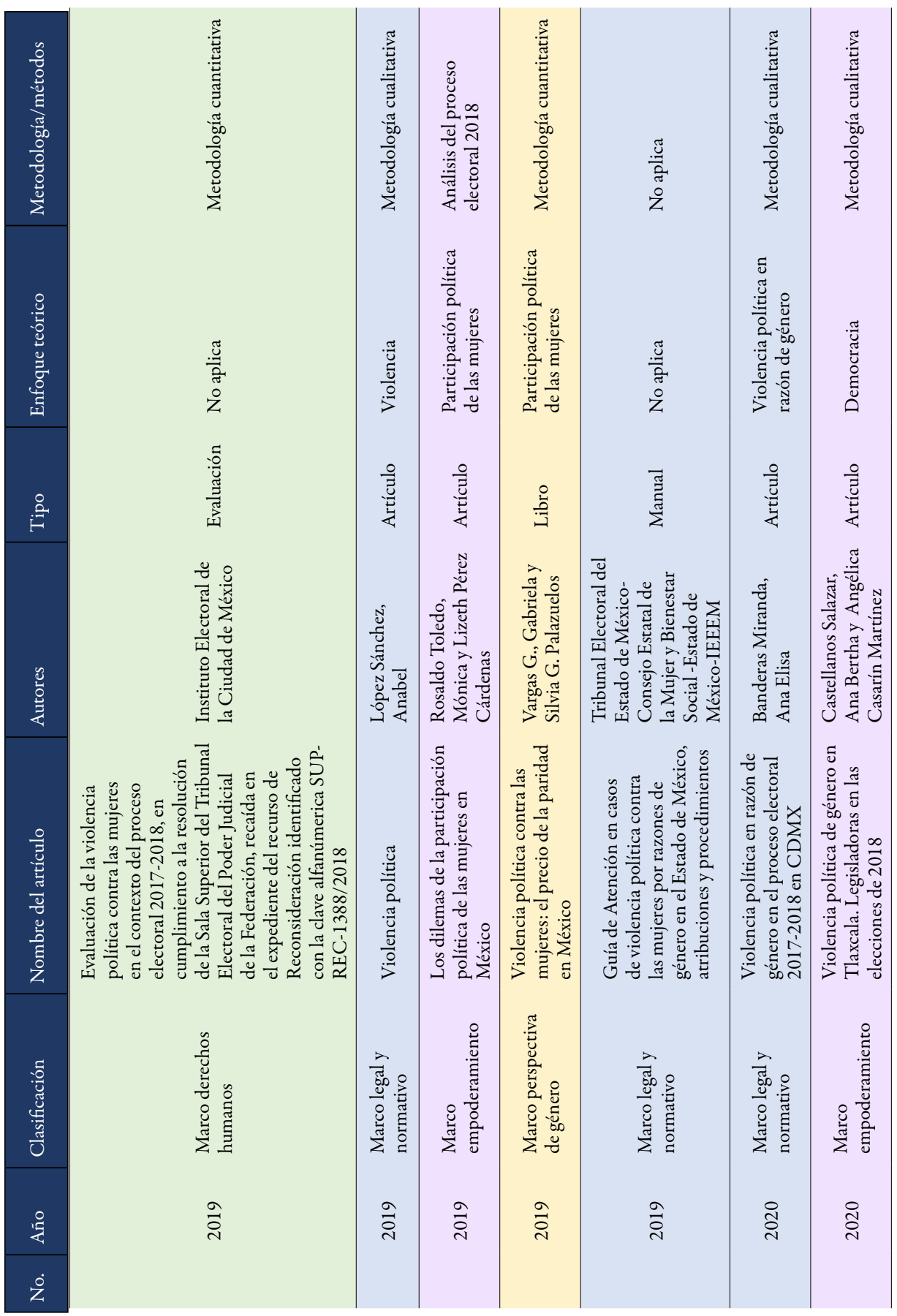


Gloria Jovita Guadarrama Sánchez y Emma del Carmen Aguilar Pinto Las diversas lecturas del concepto de violencia politica en razón de género en México (2010-2020)

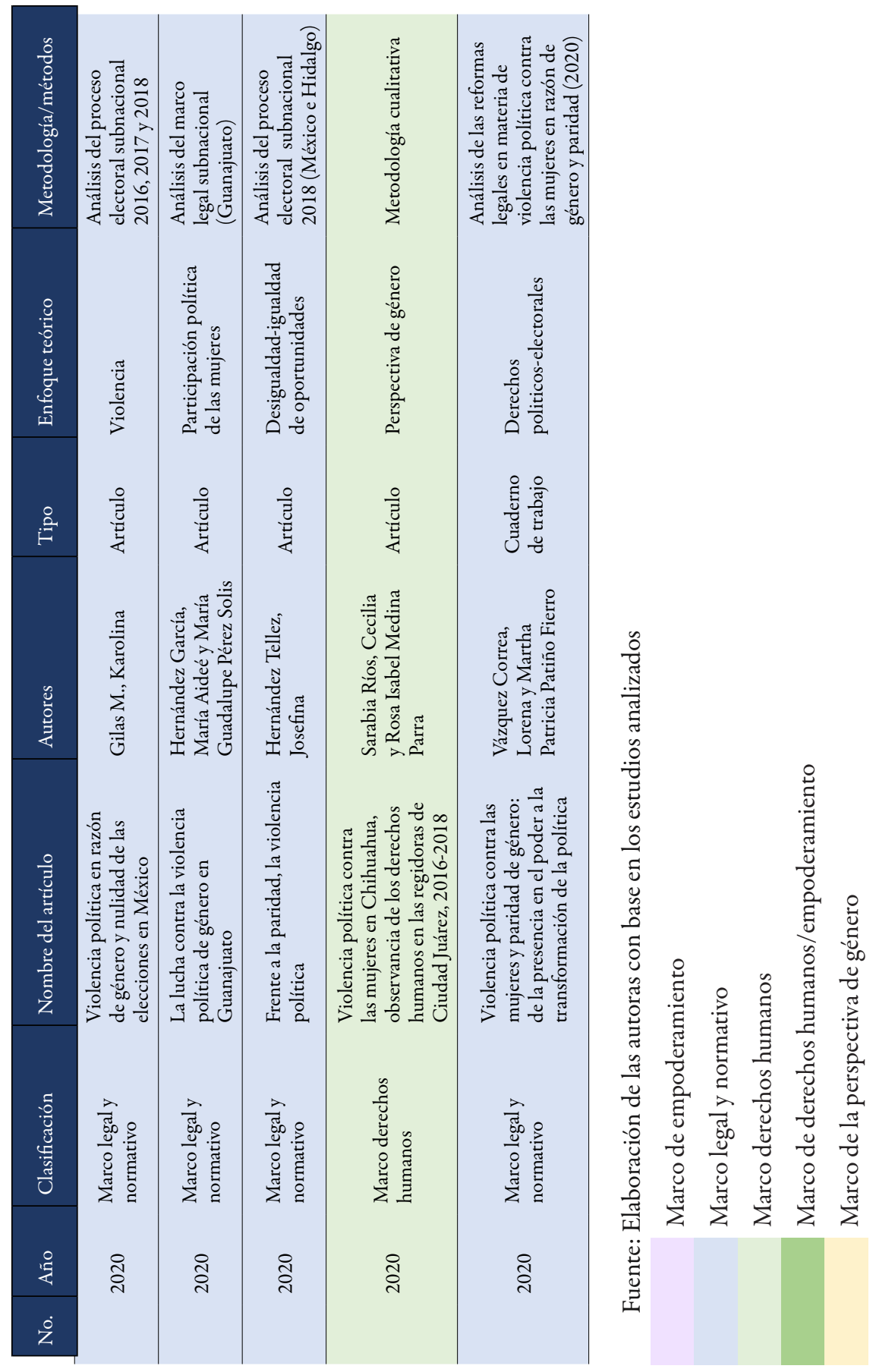


Anexo 2

\section{Enfoque teóricos y metodologías}

\begin{tabular}{|c|c|c|c|c|}
\hline Enfo+A4:F24ques teóricos & Cantidad & Porcentaje & & \\
\hline Violencia & & & Metodología & Cantidad \\
\hline Participación política & 11 & 17.2 & Cualitativa & 14 \\
\hline Cuotas de género y paridad & 10 & 15.6 & $\begin{array}{l}\text { Análisis de procesos } \\
\text { electorales (federal y } \\
\text { subnacional) }\end{array}$ & 12 \\
\hline Perspectiva de género & 9 & 14.1 & $\begin{array}{l}\text { Análisis del marco } \\
\text { legal (federal y } \\
\text { subnacional) }\end{array}$ & 12 \\
\hline Derechos político-electorales & 7 & 10.9 & $\begin{array}{l}\text { Estudios exploratorios } \\
\text { (bibliográficos- } \\
\text { hemerográficos) }\end{array}$ & 9 \\
\hline $\begin{array}{l}\text { No aplica (protocolos, guías, } \\
\text { evaluaciones) }\end{array}$ & 8 & 10.9 & $\begin{array}{l}\text { No aplica (protocolos, } \\
\text { manuales, guías) }\end{array}$ & 8 \\
\hline $\begin{array}{l}\text { Desigualdad/igualdad de } \\
\text { oportunidades }\end{array}$ & 4 & 7.8 & Cuantitativa & 4 \\
\hline Democracia & 1 & 1.6 & $\begin{array}{l}\text { Análisis de reformas } \\
\text { político-electorales }\end{array}$ & 3 \\
\hline Institucionalismo feminista & 1 & 17.2 & Cuanti-cualitativa & 2 \\
\hline Total & 64 & 100 & Total & 64 \\
\hline Técnicas & Cantidad & Porcentaje & $\begin{array}{l}\text { Fuentes de } \\
\text { información }\end{array}$ & Cantidad \\
\hline
\end{tabular}

Análisis de información

(revisión bibliográfica y/o

hemerográfica)

32

50.0

Entrevistas (semi-estructuradas,

flexibles)

$10 \quad 15.6 \quad$ Secundarias

44

No aplica (protocolos,

\begin{tabular}{lcc} 
manuales, guías) & 10 & 15.6 \\
\hline Análisis estadístico descriptivo & 4 & 6.3
\end{tabular}

Entrevisas en profundidad,

diario de campo y observación

participante (etnografía)

\begin{tabular}{llll}
\hline Encuesta & 2 & 3.1 & Primarias \\
\cline { 1 - 2 } Estudios de caso & 1 & 1.6 \\
\cline { 1 - 2 } Perfiles y trayectorias políticas & 1 & 1.6 & \\
\hline
\end{tabular}

Fuente: Elaboración de las autoras con base en los estudios analizados. 
Gloria Jovita Guadarrama Sánchez y Emma del Carmen Aguilar Pinto

Las diversas lecturas del concepto de violencia politica en razón de género en México (2010-2020)

\section{Anexo 3 \\ Palabras clave}

No aplica (capítulos de libro, libros, manuales, protocolos)

Violencia política contra las mujeres /hacia las mujeres/violencia política de género

Mujeres

Alcaldesas/cabildos/cargos de elección popular

Cuotas de género/género

Participación política

Violencia política

Derechos

Paridad

Políticas de desarrollo/mujeres

Total

Fuente: Elaboración de las autoras con base en los estudios analizados. 


\section{Gráfica 1}

\section{Estudios según tipo de texto (2010-2020)}

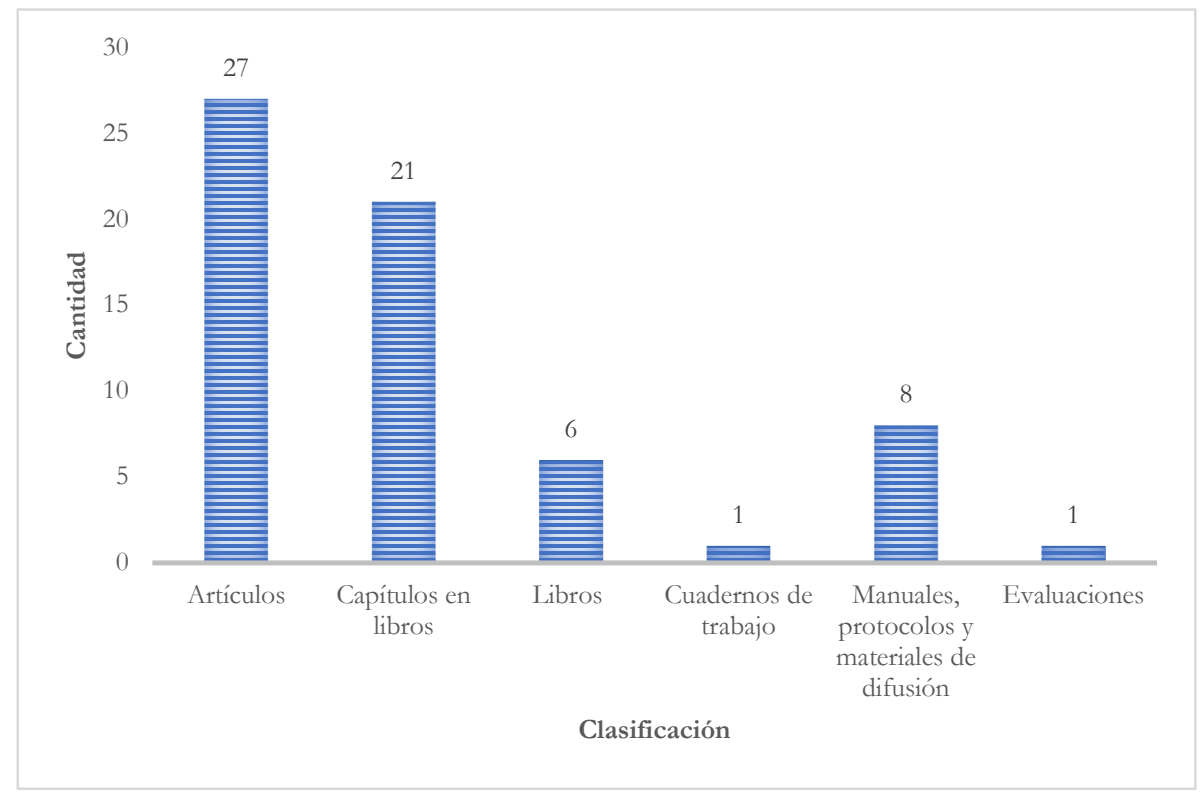

Fuente: Elaboración de las autoras con base en los estudios analizados. 
Gloria Jovita Guadarrama Sánchez y Emma del Carmen Aguilar Pinto Las diversas lecturas del concepto de violencia politica en razón de género en México (2010-2020)

\section{Gráfica 2}

\section{Estudios por año de publicación (2010-2020)}

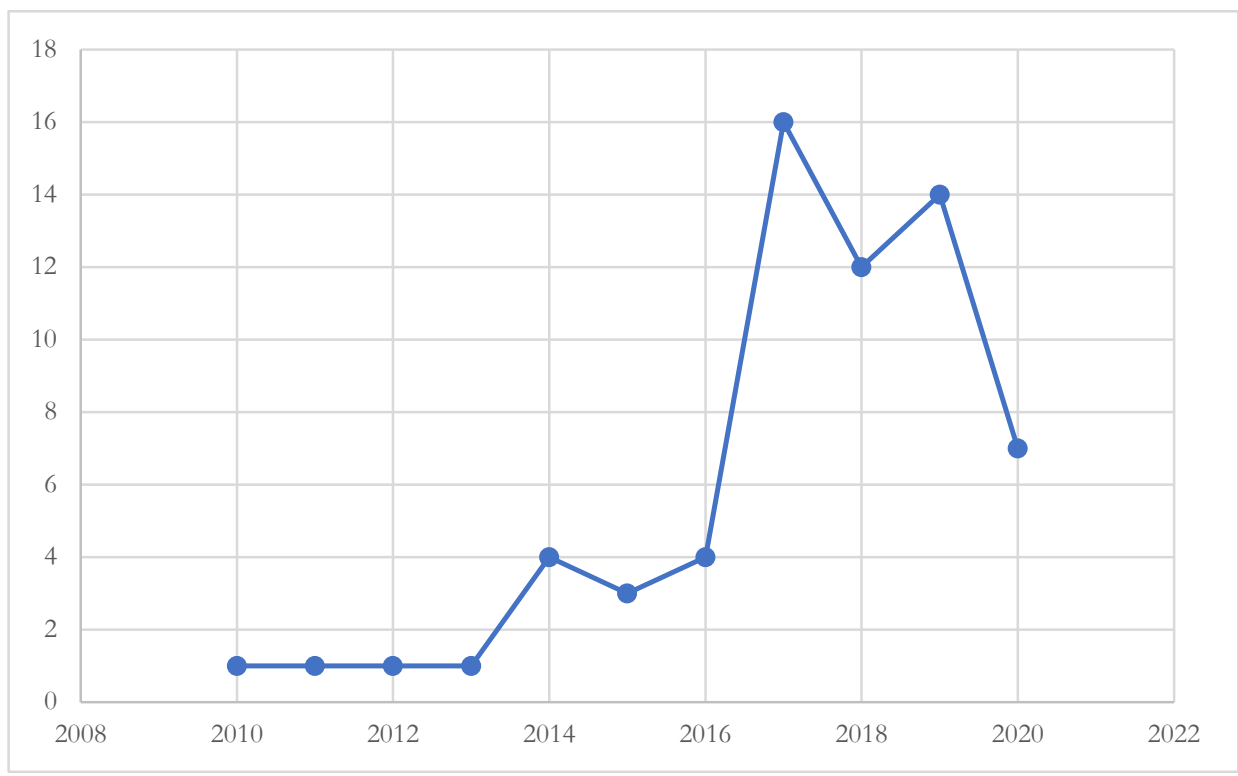

Fuente: Elaboración de las autoras con base en los estudios analizados. 


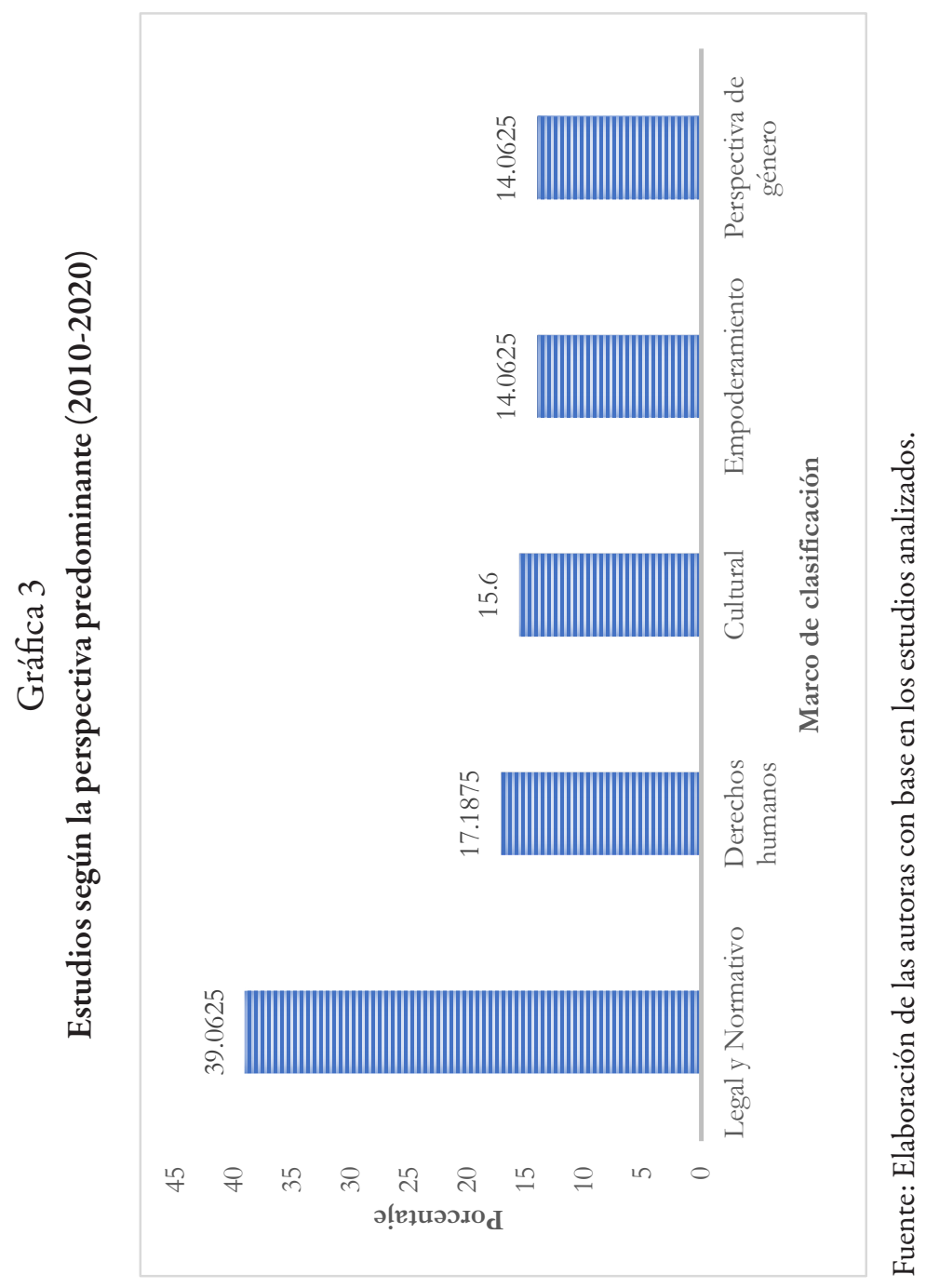


Gloria Jovita Guadarrama Sánchez y Emma del Carmen Aguilar Pinto Las diversas lecturas del concepto de violencia politica en razón de género en México (2010-2020)

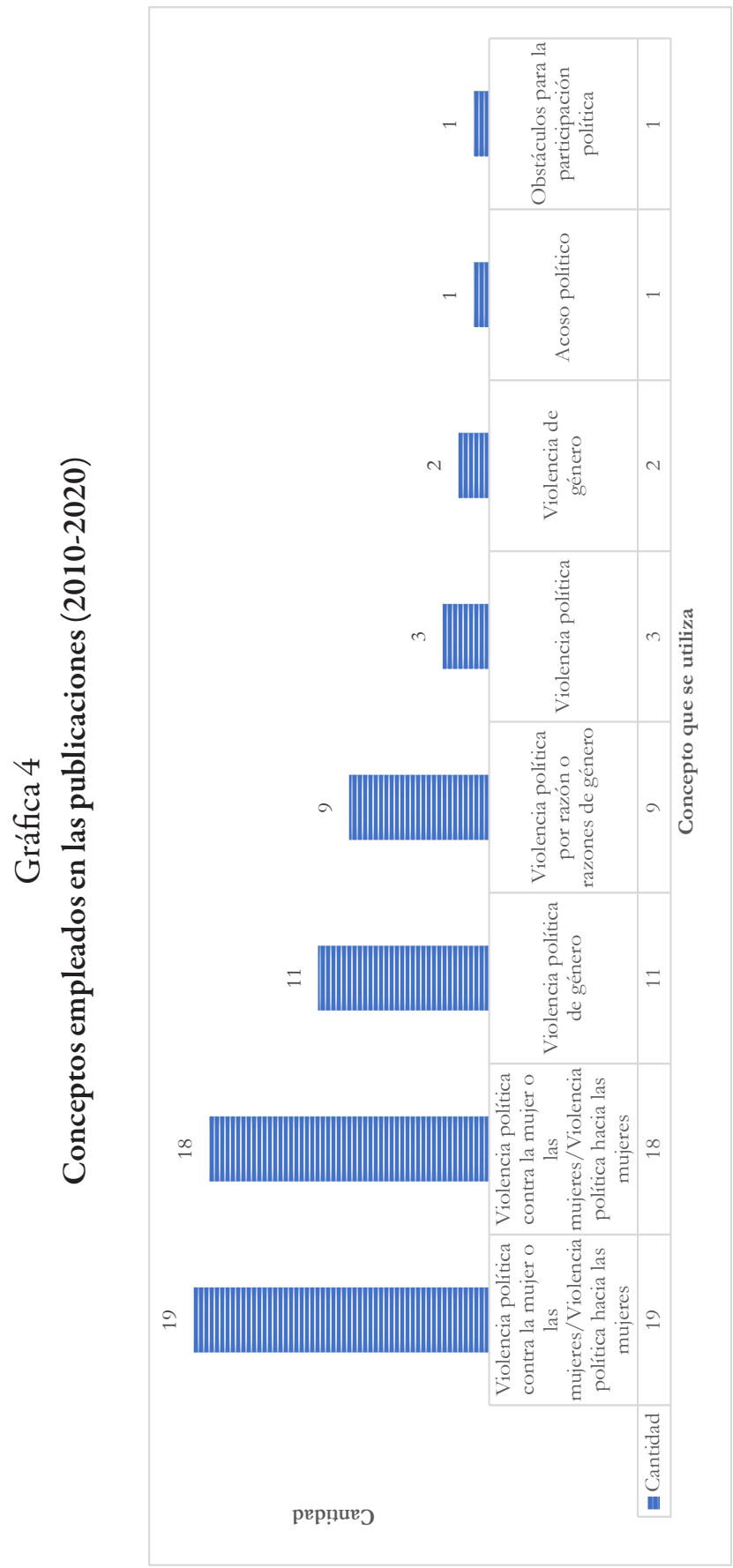

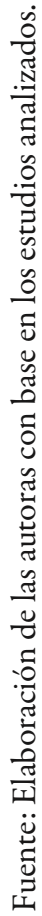


Gloria Jovita Guadarrama Sánchez. Doctora en Ciencias Políticas y Sociales por la Universidad Nacional Autónoma de México y miembro del Sistema Nacional de Investigadores, nivel II. Actualmente se desempeña como Profesora Investigadora en El Colegio Mexiquense, A. C. Sus líneas de investigación son: instituciones, políticas públicas, género, asistencia social, sociedad civil y tercer sector. Publicaciones recientes: Guadarrama Sánchez, Gloria Jovita (2019), "El modelo de fundaciones comunitarias en México", en Cooperativismo \& Desarrollo, vol. 27, núm. 115. DOI: 10.16925/23824220.2019.02.07 Disponible en: https://revistas.ucc.edu.co/index.php/co/ article/view/2965; Pliego Alvarado, Esmeralda y Guadarrama Sánchez, Gloria Jovita (2019), "Gobernanza y derecho al agua: prácticas comunes y particularidades de los comités comunitarios de agua potable”, en Sociedady Ambiente, vol. 20. DOI: 10.31840/sya.v0i20.1992 Disponible en: http:// revistas.ecosur.mx/sociedadyambiente/index.php/sya/article/view/1992; Guadarrama Sánchez, Gloria Jovita et al. [coordinadoras] (2019), ¿Problemas complejos, soluciones nuevas? Debates sobre el desarrollo social sustentable en el Estado de México, México: El Colegio Mexiquense, A. C.

Emma del Carmen Aguilar Pinto. Doctora en Ciencias en Ecología y Desarrollo Sustentable por el Colegio de la Frontera Sur y miembro del Sistema Nacional de Investigadores, nivel C. Ha sido profesora universitaria en la Universidad Autónoma de Chiapas de 2000 a 2018, impartió cursos de licenciatura y maestría en las modalidades presencial y a distancia en distintos programas académicos de la Universidad Autónoma de Chiapas. Realizó una estancia de investigación posdoctoral en el Colegio Mexiquense A. C. de 2018 a 2020. Sus líneas de investigación son: género, políticas públicas, empoderamiento y violencia. Publicaciones recientes: Guadarrama Sánchez, Gloria Jovita y Aguilar Pinto, Emma del Carmen (2019), Deshilando la madeja. Algunos hilos en la trama de la investigación académica sobre mujeres y género en México, México: El Colegio Mexiquense, A. C.; Aguilar Pinto, Emma del Carmen et al. (2017), "Microcrédito y pobreza. La experiencia del programa Microempresas Sociales de Banmujer en Chiapas", en Economia, sociedad y territorio, vol. 17, núm. 55, DOI: 10.22136/est2017885 Disponible en: https://est.cmq.edu.mx/index.php/est/article/view/885; Aguilar Pinto, Emma del Carmen et al. (2017), "Mujeres, empoderamiento y microcrédito. El programa de microempresas sociales de Banmujer en Chiapas”, en Agricultura, sociedad y desarrollo, DOI: 10.22231/asyd.v14i3.646 Disponible en: http://revista-asyd.mx/index.php/asyd/article/view/646. 